\title{
Association between the Type of Workplace and Lung Function in Copper Miners
}

\author{
Anna Skoczyńska, ${ }^{1}$ Leszek Gruszczyński, ${ }^{2}$ Anna Wojakowska, ${ }^{1}$ Marek Ścieszka, ${ }^{2}$ \\ Barbara Turczyn, ${ }^{1}$ and Edward Schmidt ${ }^{2}$ \\ ${ }^{1}$ Department of Internal and Occupational Diseases and Hypertension, Wrocław Medical University, Borowska 213, \\ 50-556 Wrocław, Poland \\ ${ }^{2}$ The Copper Health Center, M. Skłodowskiej-Curie 66, 59-301 Lubin, Poland
}

Correspondence should be addressed to Anna Skoczyńska; anna.skoczynska@umed.wroc.pl

Received 10 January 2016; Revised 7 March 2016; Accepted 29 March 2016

Academic Editor: Laurian Zuidmeer-Jongejan

Copyright (C) 2016 Anna Skoczyńska et al. This is an open access article distributed under the Creative Commons Attribution License, which permits unrestricted use, distribution, and reproduction in any medium, provided the original work is properly cited.

The aim of the analysis was to retrospectively assess changes in lung function in copper miners depending on the type of workplace. In the groups of 225 operators, 188 welders, and 475 representatives of other jobs, spirometry was performed at the start of employment and subsequently after 10, 20, and 25 years of work. Spirometry Longitudinal Data Analysis software was used to estimate changes in group means for $\mathrm{FEV}_{1}$ and FVC. Multiple linear regression analysis was used to assess an association between workplace and lung function. Lung function assessed on the basis of calculation of longitudinal FEV1 (FVC) decline was similar in all studied groups. However, multiple linear regression model used in cross-sectional analysis revealed an association between workplace and lung function. In the group of welders, FEF75 was lower in comparison to operators and other miners as early as after 10 years of work. Simultaneously, in smoking welders, the $\mathrm{FEV}_{1} / \mathrm{FVC}$ ratio was lower than in nonsmokers $(p<0,05)$. The interactions between type of workplace and smoking $(p<0,05)$ in their effect on FVC, FEV1, PEF, and FEF50 were shown. Among underground working copper miners, the group of smoking welders is especially threatened by impairment of lung ventilatory function.

\section{Introduction}

Copper miners working underground are exposed to mine gases containing, among other things, nitric oxides. Endogenous nitric oxide (NO) plays key roles in lung biology, being involved in pulmonary neurotransmission, as well as host defense, airway and vascular smooth muscle relaxation, mucociliary clearance, airway mucus secretion, inflammation, and cytotoxicity $[1,2]$. Simultaneously, endogenous NO has been implicated in the pathophysiology of lung diseases [3]. The production of NO under oxidative stress conditions generates strong oxidizing agents (reactive nitric species) that may influence the development and the course of chronic inflammatory airway diseases such as asthma, cystic fibrosis, bronchopulmonary dysplasia, lymphangioleiomyomatosis, and pulmonary hypertension [4-7].

On the other hand, the respiratory system is known to be critical for toxicity of exogenous nitric oxides. Nitric dioxide $\left(\mathrm{NO}_{2}\right)$ and nitric oxide, dissolving in water contained in the bronchial mucus, form nitric acid and nitrous acid. These acids may produce acute pulmonary injury due to inhalation of vapors and gases originating from nitric acid solutions. Acute poisoning may occur as a result of shortterm exposure to nitric oxides at high concentrations (94$7500 \mathrm{mg} / \mathrm{m}^{3}$ ) in the course of mining disasters, breakdowns, and accidents. Nitric oxides in very high concentrations can cause immediate death, toxic pulmonary edema occurring within 48 hours, pneumonia [8], or acute respiratory distress syndrome [9]. By combining with the alkaline substances contained in the mucous secretion, a part of nitric and nitrous acids is converted into nitrite, which may cause methemoglobinemia [10]. Thus, the consequence of acute or chronic exposition to nitric oxides is respiratory failure from hypoxemia and, next, hypercapnia. The result of chronic, repeated exposure to nitric oxides can be fibrous chronic 
bronchitis, diffuse interstitial lung fibrosis with emphysema, and bronchial hyperreactivity. It was documented that chronic, occupational exposure to nitric oxides is associated with increased susceptibility to respiratory infections [11] and with changes in spirometric indices $[12,13]$. The toxic effect of nitric oxides is investigated in view of the recent debate on European limits, recommended by the Scientific Committee on Occupational Exposure Limit Values (SCOEL) [14, 15].

Few studies have shown that miners working under the ground may be chronically exposed to various levels of nitric oxides. The sources of $\mathrm{NO}_{2}$ and $\mathrm{NO}$ are mine gases, diesel engine emissions, welding technology, the use of explosives for blasting, and also smoking $[16,17]$. The aim of this analysis was to assess changes in lung function in copper miners potentially exposed to nitric oxides over 25 years of work, based on the results of repeatedly performed spirometry tests. Another goal was to examine whether lung dysfunction in underground miners is dependent on the type of workplace.

\section{Material and Methods}

2.1. Workers. Results of spirometric tests, which have been conducted in 888 miners during their 25 years of employment at the same copper mine, between 1980 and 2005, in Poland, in Lower Silesia, were analyzed. Miners were working underground as operators (225 men), welders (188 men), and other workers (475 men): mechanics, electricians, transport workers, and hewers (miners employed in the direct obtaining of excavated material). The samples of mine air were taken every month to determine time weighted average (TWA) and a short-term exposure limit (STEL) for nitric oxides. The determined TWA concentrations ranged from subdetectable (most often) to $2,02 \mathrm{mg} / \mathrm{m}^{3}$ (rarely in 20012009), that is, below Maximum Allowable Concentration (MAC). The short-term exposure limit for nitric dioxide $\left(1,5 \mathrm{mg} / \mathrm{m}^{3}\right)$ was sometimes exceeded and in some measurements in 2007 reached as much as $3,96 \mathrm{mg} / \mathrm{m}^{3}$.

Anthropometric data (body weight and height) were collected in local health centre, using calibrated equipment and standardized methodology. Body mass index (BMI) was estimated as the ratio of weight to height squared $\left(\mathrm{kg} / \mathrm{m}^{2}\right)$.

Spirometry was performed on workers four times: at the start of employment (between 1980 and 1983) and then 10 years after (between 1989 and 1991), 20 years after (between 1998 and 2000), and 25 years after the beginning of work (between 2003 and 2005). The procedures were in accordance with ethical standards and the Helsinki Declaration of 1975, as revised in 1983.

At the time of the first spirometry, among the miners, 435 men were nonsmokers and 354 were smokers (average rate: 20 cigarettes $\times 8,1 \pm 5,6$ years of smoking), and in 99 cases there was no information on smoking. A respiratory disease was diagnosed in 15 workers: pneumoconiosis (in eight miners) or allergic respiratory disease (in seven workers). There were no data on respiratory diseases in 108 men. In some groups of workers, results of blood count were analyzed. The number of miners, including smokers and men with respiratory disease, has changed over the period of employment, as shown in Table 1. The largest decrease in the number of obtained spirometry results concerned the study that was performed in 1998-2000 and was due to the loss of part of spirometry tests' results during transfer of the archive. The biggest number of missing results (50\%) concerned the group of "other" miners. However, in groups of operators and welders, losses were significantly lower $(2.6 \%$ and $23 \%$, resp.), so in the analysis (except for the analysis using the SPIROLA program) also the data from 1998-2000 was taken into account.

2.2. Equipment and Interpretation. Spirometry was carried out at first according to American Thoracic Society criteria (as described in [18]) and then, since 1993, according to ERS guidelines (published in [19]). Tests were performed on Spirolab spirometer (Roma, Italy). Patients were assessed for contraindications to spirometry; data on the height, body mass, and other required parameters (age, gender, and ethnicity) were collected. The procedure was explained to the patient, a nose clip was applied, and a minimum of three acceptable VC manoeuvres were obtained. Repeatability criteria were met when there was no more than $100 \mathrm{~mL}$ ideally (and certainly no more than $150 \mathrm{~mL}$ in the occasional highly variable patient) between each blow. Patient was verbally encouraged to continue to exhale as long as possible and, next, VC manoeuvres (no more than four) and FVC manoeuvres (a minimum of three acceptable, maximum eight) were obtained. The best value was recorded for forced expiratory volume in the first second $\left(\mathrm{FEV}_{1}\right)$, forced vital capacity (FVC), peak expiratory flow (PEF), and four parameters of forced expiratory flow (FEF): $\mathrm{FEF}_{25}$, $\mathrm{FEF}_{50}, \mathrm{FEF}_{75}$, and $\mathrm{FEF}_{25-75}$. The mean $\mathrm{FEV}_{1} / \mathrm{FVC}$ ratio (forced expiratory volume in the first second, expressed as a percentage of the forced vital capacity) was calculated. The technical accuracy of performed spirometry tests and the precision of collected data were monitored by technicians trained in ATS standards. Inspection of flow-volume curves served to control complete exhalation, indicated by gradual flow drop to zero. Interpretation of the results was based on guidelines published in 2005 by the experts of the American Thoracic Society (ATS) and European Respiratory Society (ERS) concerning the correctness of the implementation and evaluation of spirometry $[20,21]$. In case of $\mathrm{FEV}_{1}, \mathrm{FVC}$, and $\mathrm{FEV}_{1} / \mathrm{FVC}$, a lower limit for normal value (LLN) which corresponds to the fifth percentile in healthy nonsmokers and/or a lower limit for normal decline were estimated [22]. NIOSH (National Institute for Occupational Safety and Health) Spirometry Longitudinal Data Analysis (SPIROLA v3.0.2) software was used, which monitors group means for $\mathrm{FEV}_{1}$ and $\mathrm{FVC}$ in relation to mean predicted values based on group demographics (age, height, gender, and ethnicity/race). For the first 8 years of follow-up, SPIROLA uses the limit of longitudinal decline (LLD) which takes into account expected within-person variation in $\mathrm{FEV}_{1}$ or $\mathrm{FVC}$ and the duration of follow-up. After 8 years of follow-up, the age at which the individual is projected to develop lung function impairment is considered in the evaluation. Using SPIROLA program, we also evaluated whether $\mathrm{FEV}_{1}$ and FVC slopes for studied cohort exceeded $40 \mathrm{~mL}$ per year (referential date for decline 
TABLE 1: Characteristics of copper miners monitored by spirometry over 25 years of work. Comparison of the welders group to the group of operators and other miners.

\begin{tabular}{|c|c|c|c|c|}
\hline & The first study & After 10 years & After 20 years & After 25 years \\
\hline All groups $(n)$ & 888 & 857 & 603 & 739 \\
\hline Age $(y r)$, mean $(S D)$ & $29,5 \pm 4,2$ & $39,5 \pm 4,2$ & $48,7 \pm 3,8$ & $54,2 \pm 4,1$ \\
\hline Height $(\mathrm{cm})$, mean $(\mathrm{SD})$ & $174,9 \pm 6,0$ & $174,9 \pm 6,2$ & $173,9 \pm 6,0$ & $175,2 \pm 6,3$ \\
\hline Weight (kg), median (IQR) & $80,0(72,88)$ & $82,0(74,91)$ & $84,0(76,93)$ & $86,0(79,95)$ \\
\hline BMI $\left(\mathrm{kg} / \mathrm{m}^{2}\right)$, median (IQR) & $26,1(24,1,28,4)$ & $26,7(24,7,29,3)$ & $27,7(25,30,1)$ & $27,9(25,8,30,4)$ \\
\hline Smokers $(n / \%)$ & $354 / 44,9 \%$ & $371 / 43,5 \%$ & $257 / 42,9 \%$ & $280 / 38,0 \%$ \\
\hline Period of smoking (yr) & $8,1 \pm 5,6$ & $13,1 \pm 5,9$ & $18,8 \pm 7,0$ & $22,3 \pm 7,8$ \\
\hline Nonsmokers $(n / \%)$ & $435 / 55,1 \%$ & $480 / 56,5 \%$ & $341 / 57,1 \%$ & $456 / 62,0 \%$ \\
\hline $\begin{array}{l}\text { Respiratory disease: total } \\
\text { (coniosis/allergy) }(n)\end{array}$ & $15(8 / 7)$ & $14(8 / 6)$ & $8(6 / 2)$ & $15(8 / 7)$ \\
\hline Operators group $(n)$ & 225 & 222 & 219 & 144 \\
\hline Age $(y r)$, mean $(S D)$ & $26,8 \pm 3,2$ & $36,8 \pm 3,2$ & $46,9 \pm 3,3$ & $52,7 \pm 3,7$ \\
\hline Height $(\mathrm{cm})$, mean $(\mathrm{SD})$ & $174,3 \pm 6,1$ & $174,4 \pm 6,1$ & $174,7 \pm 6,3$ & $174,9 \pm 6,0$ \\
\hline Weight (kg), median (IQR) & $80,0(71,88)$ & $82,0(73,91)$ & $84,0(76,95)$ & $87,0(80,96)$ \\
\hline BMI $\left(\mathrm{kg} / \mathrm{m}^{2}\right)$, median (IQR) & $25,8(23,7,28,6)$ & $26,7(24,5,29,3)$ & $27,5(25,29,9)$ & $28,4(26,1,30,9)$ \\
\hline Smokers $(n / \%)$ & $92 / 41,3 \%$ & $97 / 44,7 \%$ & $95 / 45,3 \%$ & $47 / 32,6 \%$ \\
\hline Nonsmokers $(n / \%)$ & $132 / 58,7 \%$ & $120 / 55,3 \%$ & $122 / 55,7 \%$ & $97 / 67,4 \%$ \\
\hline “Others" group $(n)$ & 475 & 461 & 239 & 428 \\
\hline Age $(y r)$, mean $(S D)$ & $30,3 \pm 3,9$ & $40,3 \pm 3,9$ & $49,9 \pm 4,1$ & $53,9 \pm 3,8$ \\
\hline Height $(\mathrm{cm})$, mean $(\mathrm{SD})$ & $174,9 \pm 6,2$ & $175,0 \pm 6,2$ & $172,6 \pm 5,3$ & $175,3 \pm 6,2$ \\
\hline Weight (kg), median (IQR) & $80,0(72,88)$ & $82,0(73,91)$ & $81,0(74,91)$ & $86,0(78,95)$ \\
\hline BMI $\left(\mathrm{kg} / \mathrm{m}^{2}\right)$, median (IQR) & $26,1(24,1,28,4)$ & $26,5(24,5,28,9)$ & $27,5(25,30,1)$ & $27,7(25,8,30,2)$ \\
\hline Smokers $(n / \%)$ & $178 / 42,3 \%$ & $191 / 42,1 \%$ & $102 / 42,7 \%$ & $170 / 39,5 \%$ \\
\hline Nonsmokers $(n / \%)$ & $243 / 57,7 \%$ & $267 / 57,9 \%$ & $136 / 56,9 \%$ & $257 / 60,5 \%$ \\
\hline Welders group $(n)$ & 188 & 174 & 145 & 167 \\
\hline Age $(y r)$, mean $(S D)$ & $31,7 \pm 4,5^{* *}$ & $41,7 \pm 4,5^{* *}$ & $49,3 \pm 2,9^{* * *}$ & $56,4 \pm 4,3^{* * *}$ \\
\hline Height $(\mathrm{cm})$, mean $(\mathrm{SD})$ & $175,6 \pm 5,6$ & $174,8 \pm 6,4$ & $174,9 \pm 6,5$ & $174,9 \pm 6,8$ \\
\hline Weight (kg), median (IQR) & $83,0(74,90)^{* *, \circ \circ}$ & $84,0(77,91)^{* *, \circ \circ}$ & $86,0(80,95)^{* *, \circ \circ}$ & $85,5(78,96)$ \\
\hline BMI $\left(\mathrm{kg} / \mathrm{m}^{2}\right)$, median (IQR) & $27,4(25,3,29,1)^{* *, \circ}$ & $27,4(25,3,27,2)$ & $28,4(25,31,1)$ & $28,1(25,8,30,3)$ \\
\hline Smokers $(n / \%)$ & $84 / 58,4 \%^{\circ 00}$ & $83 / 46,7 \%^{\circ 00}$ & $60 / 41,9 \%$ & $63 / 37,7 \%^{\circ 00}$ \\
\hline Nonsmokers $(n / \%)$ & $60 / 41,6 \%{ }^{\circ 00}$ & $93 / 53,3 \%^{\circ 00}$ & $83 / 58,1 \%^{\circ}$ & $104 / 62,3 \%^{\circ \circ}$ \\
\hline
\end{tabular}

using within-person standard deviation of $4 \%$ ) and, on the basis of risk list function, determined how many subjects met criteria for abnormality.

2.3. Statistical Analysis. The impact of the type of workplace on lung function in copper miners was investigated as the main objective of this analysis. The independent variable was defined as operators, welders, or "others" and was individually analyzed in relation to each lung function outcome in the multiple linear regression model. This analysis was performed retrospectively fourfold, including results of spirometry obtained at the start of employment and after 10,20 , and 25 years of work. The following variables were included as potential confounders in the analysis of lung function: age, height, weight, BMI, presence of respiratory disease, and smoking status.

Spirometric indices were presented as mean \pm SD, median and IQR, and percentile: 5\% and 95\%. Depending on the type of variable distribution, parametric or nonparametric methods of analysis were used. In the case of normal distribution, $t$-tests including paired test for dependent samples were applied, and a statistical significance between means was calculated using ANOVA test. In case of qualitative variables, nonparametric tests were used. Two-way analysis of variance (using workplace and smoking as independent factors) was also applied with one- or multidimensional significance tests. Correlations between variables were checked using Spearman coefficient. $p$ value less than 0,05 was accepted as statistically 
TABLE 2: $\mathrm{FEV}_{1} / \mathrm{FVC}$ ratio in the studied groups of copper miners at the start of employment (the first spirometry) and 10,20 , and 25 years later.

\begin{tabular}{|c|c|c|c|c|c|c|c|}
\hline & $n$ & Mean \pm SD & Q25 & Median & Q75 & 5th percentile & 95th percentile \\
\hline & \multicolumn{7}{|c|}{ The first study } \\
\hline Operators & 220 & $84,7 \pm 13,6$ & 78,7 & 86,0 & 91,4 & 63,9 & 97,4 \\
\hline Others & 465 & $88,8 \pm 52,2$ & 81,6 & 87,2 & 92,3 & 69,7 & 97,8 \\
\hline Welders & 178 & $84,9 \pm 8,92$ & 81,3 & 85,6 & 90,2 & 68,0 & 96,6 \\
\hline \multirow[t]{2}{*}{ Total } & 863 & $85,6 \pm 11,3$ & 81,2 & 86,4 & 91,7 & 68,0 & 97,2 \\
\hline & \multicolumn{7}{|c|}{ After 10 years } \\
\hline Operators & 221 & $84,9 \pm 8,27$ & 80,5 & 85,8 & 89,9 & 74,9 & 93,4 \\
\hline Others & 456 & $84,5 \pm 52,2$ & 81,6 & 87,2 & 92,3 & 75,6 & 96,5 \\
\hline Welders & 173 & $84,3 \pm 7,34$ & 81,1 & 85,4 & 89,1 & 75,8 & 92,1 \\
\hline \multirow[t]{2}{*}{ Total } & 850 & $84,5 \pm 7,60^{* *}$ & 80,5 & 85,3 & 89,2 & 75,5 & 92,6 \\
\hline & \multicolumn{7}{|c|}{ After 20 years } \\
\hline Operators & 219 & $82,5 \pm 7,05$ & 79,2 & 83,1 & 86,5 & 74,3 & 89,5 \\
\hline Others & 239 & $83,9 \pm 8,36$ & 78,9 & 83,8 & 87,8 & 73,9 & 92,5 \\
\hline Welders & 144 & $83,5 \pm 8,22$ & 80,1 & 83,8 & 86,6 & 73,9 & 91,4 \\
\hline \multirow[t]{2}{*}{ Total } & 602 & $83,7 \pm 11,8^{* * *}$ & 79,3 & 85,6 & 86,9 & 74,4 & 91,1 \\
\hline & \multicolumn{7}{|c|}{ After 25 years } \\
\hline Operators & 144 & $82,5 \pm 6,60$ & 79,6 & 83,1 & 85,8 & 73,7 & 89,6 \\
\hline Others & 429 & $82,8 \pm 11,9$ & 78,7 & 83,4 & 86,2 & 73,6 & 90,7 \\
\hline Welders & 166 & $81,7 \pm 6,90$ & 77,8 & 82,3 & 85,6 & 73,3 & 89,6 \\
\hline Total & 739 & $82,5 \pm 10,1^{* * *}$ & 78,7 & 85,5 & 86,0 & 73,5 & 90,1 \\
\hline
\end{tabular}

Paired $t$-test for dependent samples. Statistically significant difference in comparison to the results of the first spirometry performed in the group of all miners (total); ${ }^{* *} p<0,01 ;{ }^{* * *} p<0,001$.

significant. Analyses were carried out using STATISTICA version 12.0 .

\section{Results}

The mean height of operators, welders, and other miners was similar. At the beginning of employment, the median BMI values were greater than $25.0 \mathrm{~kg} / \mathrm{m}^{2}$ in all groups. At this time, BMI was greater than $30.0 \mathrm{~kg} / \mathrm{m}^{2}$ in 113 miners and greater than $35.0 \mathrm{~kg} / \mathrm{m}^{2}$ in 13 men. BMI in welders was higher than in remaining miners. Changes in body mass index during 25 years of work were similar in all groups of workers, whereas the age differences were not similar (Table 1). Among studied groups of miners, operators were younger, on average by 3-5 years, in comparison to welders and representatives of other jobs. The inverse linear relationship between age and $\mathrm{FEV}_{1} / \mathrm{FVC}$ ratio was shown $(r=-0,1361 ; p=0,0000)$. In the group of miners studied after 20 years of work, the inverse relationship between age and FVC $(r=-0,1971 ; p<0,0000)$ and between age and $\mathrm{FEV}_{1}(r=-0,1734 ; p<0,0000)$ was observed.

3.1. Changes in Spirometric Parameters over 25 Years of Work. In spirometry tests performed at the start of the employment and after 10, 20, and 25 years, in each group (operators, welders, and others), the mean $\mathrm{FEV}_{1} / \mathrm{FVC}$ ratio was greater than $70 \%$ (Table 2). However, in the first spirometry, in 21 (10\%) operators, $12(6 \%)$ welders, and $26(5 \%)$ other miners (in $59(6,6 \%)$ workers in total), $\mathrm{FEV}_{1} / \mathrm{FVC}$ was lower than
LLN. In this subgroup of men with reduced $\mathrm{FEV}_{1} / \mathrm{FVC}$ ratio, in ten miners ( 6 operators, 2 welders, and 2 others), also $\mathrm{FEV}_{1}$ was less than LLN. With the expiration of the employment period, the number of miners with obstructive disorders decreased; after 10 years, it was 31 men, after 20 years 26 men, and after 25 years 30 men. The number of miners with both $\mathrm{FEV}_{1} / \mathrm{FVC}$ and $\mathrm{FEV}_{1}$ lower than LLN was 3, 4, and 7 after 10, 20 , and 25 years of work, respectively.

$P$-paired test for dependent variables performed in the whole group showed a gradual, significant decrease in $\mathrm{FEV}_{1} / \mathrm{FVC}$ ratio over a 25 -year period of occupation (Table 2). The mean $\mathrm{FEV}_{1}(4,096 \pm 0,72 \mathrm{~L}$ initially) decreased in subsequent years to $3,825 \pm 0,71 \mathrm{~L}$. Using SPIROLA software, it was shown that the mean rate of $\mathrm{FEV}_{1}$ absolute decline from first to last measurement was $10.0 \mathrm{~mL} /$ year (relative decline was $0.3 \%$ /year), and mean slope for $\mathrm{FEV}_{1}$ (LLD) amounted to $-12.4 \mathrm{~mL} /$ year (relative slope: $-0.3 \% /$ year), with root mean square error (RMSE) of $117 \mathrm{~mL}$. Simultaneously, in the course of performed work, a decrease in $\% \mathrm{PEF}, \% \mathrm{FEF}_{25}$, and $\% \mathrm{FEF}_{75}$ was shown (Figure 1 versus Figure 2).

3.2. The Analysis of Spirometric Indices Depending on the Type of Underground Work. In group of copper miners employed as operators, during 25 years of follow-up, the mean group slope was $-1,0 \mathrm{~mL} /$ year, with within-person variation for the group (root mean square error, RMSE) of $329 \mathrm{~mL}$, whereas mean slope for FVC was $10 \mathrm{~mL} /$ year, with RMSE of $127 \mathrm{~mL}$. In the same period, in group of welders, mean group slope for $\mathrm{FEV}_{1}$ was $-21 \mathrm{~mL} /$ year, with RMSE of $540 \mathrm{~mL}$, and mean 


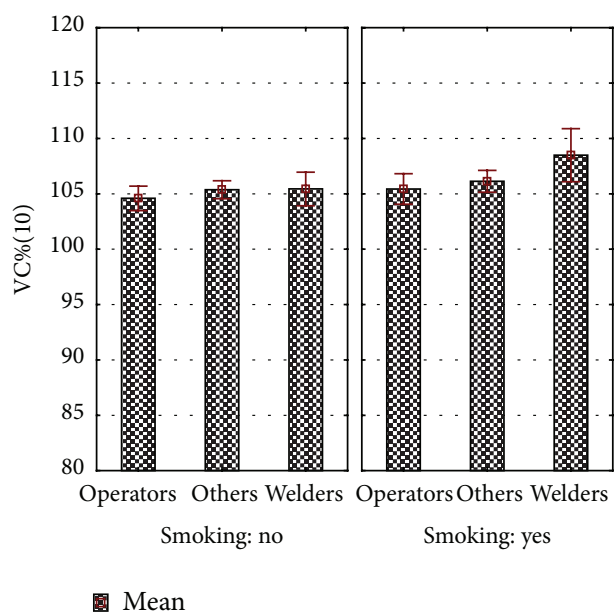

I Mean \pm SE

(a)

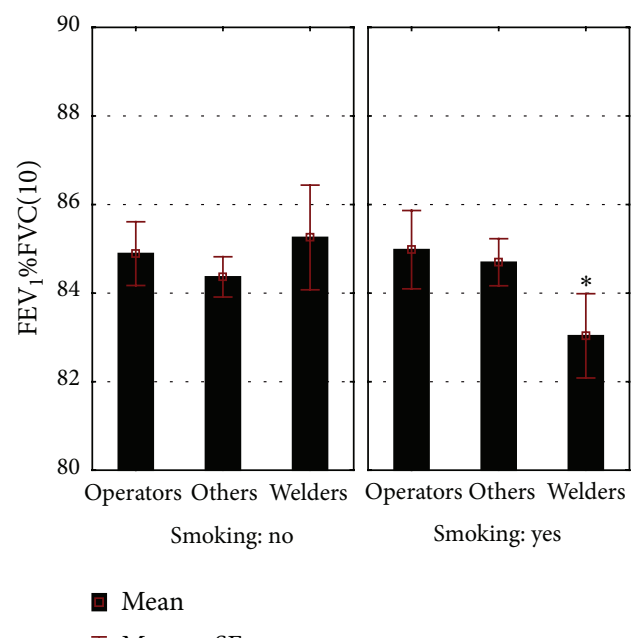

I Mean \pm SE

(c)

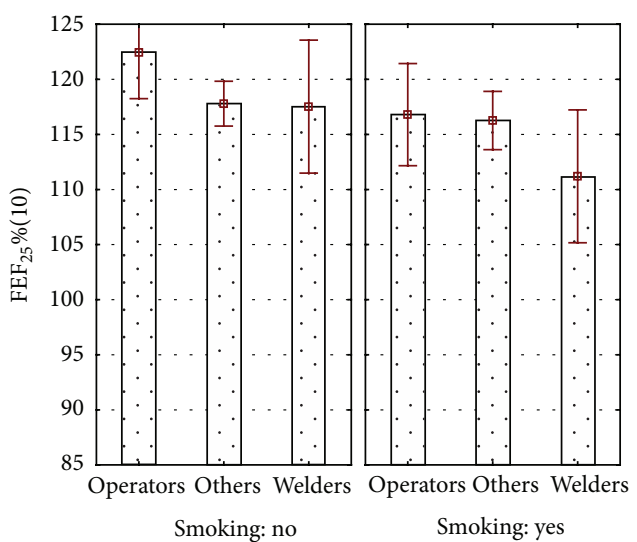

回 Mean

I Mean \pm SE

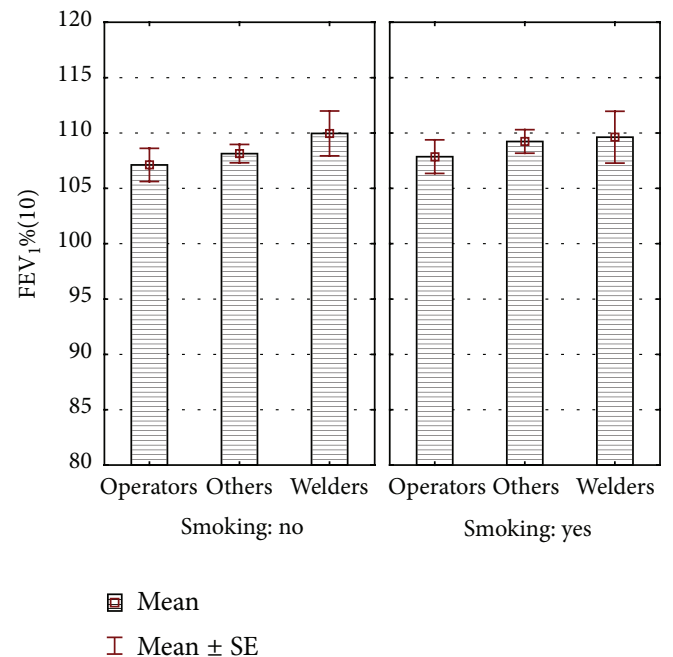

(b)

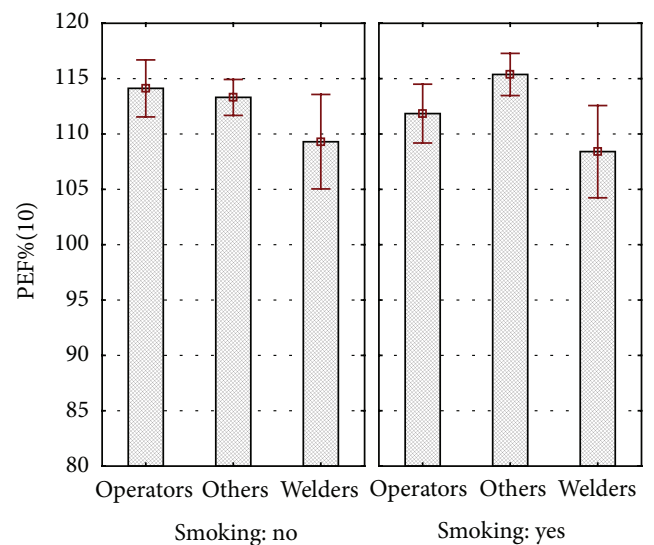

回 Mean

I Mean \pm SE

(d)

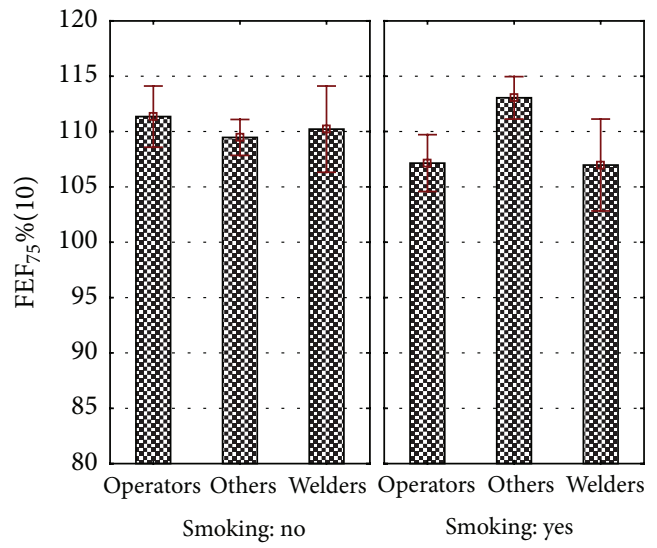

固 Mean

I Mean \pm SE

(e)

FIGURE 1: Spirometric parameters in miners after 10 years of work depending on the workplace and smoking. ${ }^{*}$ Statistically significant differences between nonsmokers and smokers; $p<0,05$. 


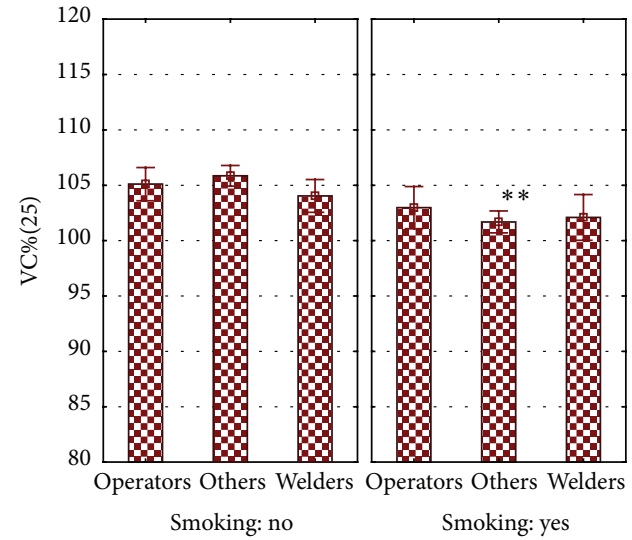

国 Mean

I Mean \pm SE

(a)

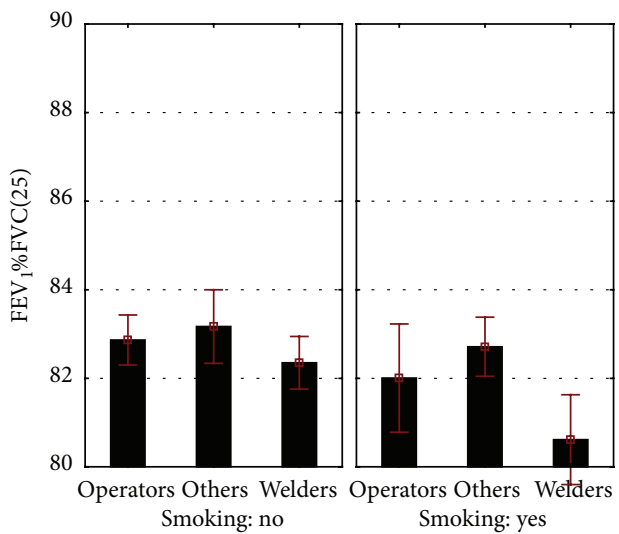

Mean

I Mean \pm SE

(c)

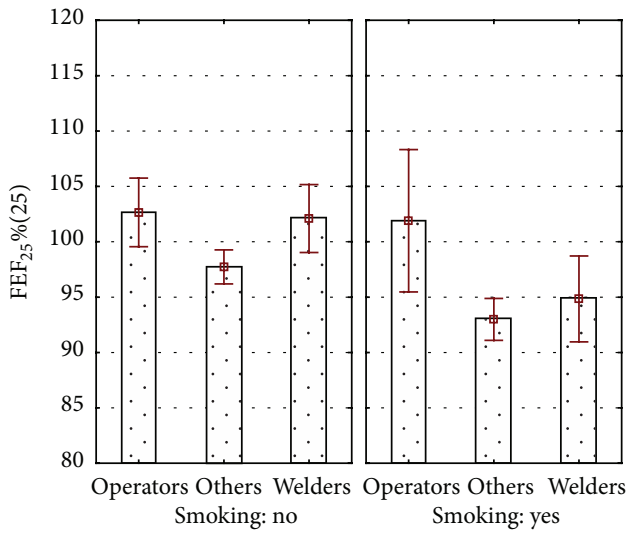

回 Mean

I Mean \pm SE

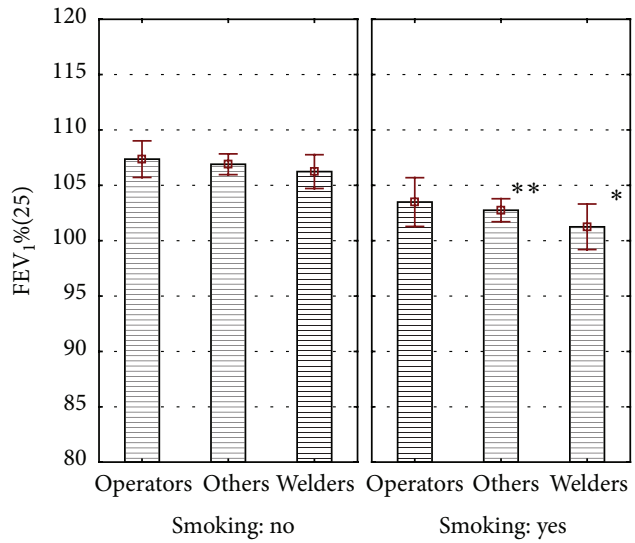

国 Mean

I Mean \pm SE

(b)

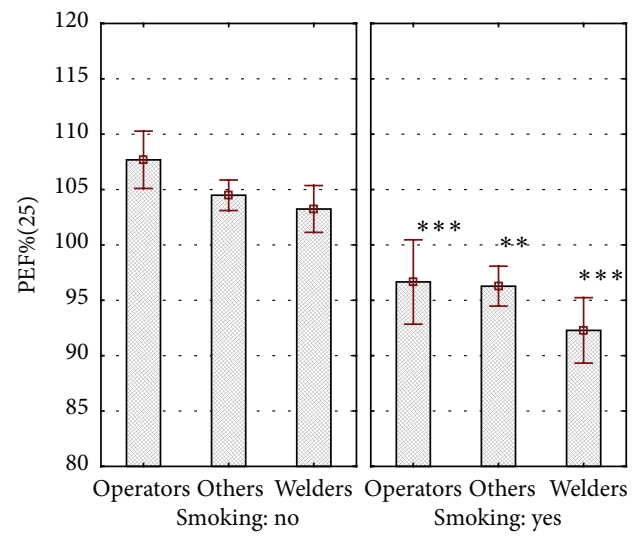

圆 Mean

I Mean $\pm \mathrm{SE}$

(d)

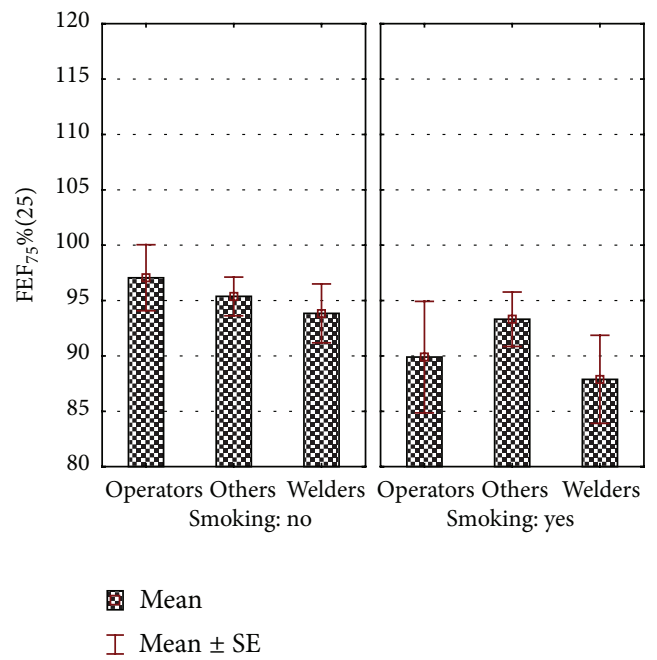

(f)

FIGURE 2: Spirometric parameters in miners after 25 years of work depending on the workplace and smoking. ${ }^{* * *, * * *}$ Statistically significant differences between nonsmokers and smokers; ${ }^{*} p<0,05 ;{ }^{* *} p<0,01 ;{ }^{* * *} p<0,001$. 
slope for FVC was $-14 \mathrm{~mL} /$ year, with RMSE of $532 \mathrm{~mL}$. In group of miners employed at other workplaces, mean group slope for $\mathrm{FEV}_{1}$ was $-8,0 \mathrm{~mL} /$ year with RMSE of $535 \mathrm{~mL}$, and for FVC it was $0,0 \mathrm{~mL} /$ year, with RMSE of $603 \mathrm{~mL}$. In risk list of SPIROLA, excessive variation for $\mathrm{FEV}_{1}(>10,1 \%)$ and/or FVC $(>7,7 \%)$ was present in $28 \%$ of operators, $17 \%$ of welders, and $24 \%$ of other miners. Trends in $\mathrm{FEV}_{1}$ and FVC over time in each group of miners were presented in Figure 3.

Significant differences in spirometric parameters between welders and other job's representatives appeared after 10 years of employment. In welders, the values of PEF $(9,8 \pm 2,7)$ and $\mathrm{FEF}_{75}(7,8 \pm 2,9)$ were lower in comparison to group of other workers $(10,3 \pm 2,5 ; p<0,05$ and $8,6 \pm 2,4 ; p<$ 0,001 , resp.) (Figure 4(a)). Simultaneously, multiple linear regression analysis did not show any significant association between workplace and lung function (Table 3 ).

After 20 years of work, significant differences between studied groups of workers included all spirometric indices (Figure 4(b)). Except for $\mathrm{FEF}_{75}$, these parameters were lower in the group called "others," in comparison to the group of operators or welders. Multiple linear regression analysis adjusted for age, height, weight, BMI, smoking, and presence of respiratory disease showed an association between workplace and lung function. The significant beta-coefficients for FVC, $\mathrm{FEV}_{1}, \mathrm{FEF}_{25-75}$, and $\mathrm{FEF}_{50}$ have been demonstrated (Table 3).

After 25 years of work, welders displayed significantly $(p<0,05)$ lower \% PEF $(99,0 \pm 22,7)$, in comparison to operators $(104,1 \pm 26,1)$ and others $(101,7 \pm 23,0)$. The mean $\mathrm{FEF}_{25}$ values in welders $(5,9 \pm 2,8)$ and "others" $(5,7 \pm 2,7)$ were lower than in operators $(7,7 \pm 5,2), p<0,05$ and $p<$ 0,01 , respectively (Figure 4(c)). Association between type of workplace and lung function parameters (FVC and PEF) was documented (Table 3).

Among all confounding factors, height and absolute values of BMI had the highest positive beta-coefficients in a linear regression model (i.e., in the group of miners studied after 20 years of work, the coefficient of correlation between $\mathrm{BMI}$ and FVC reached the value of 0,950 ), whereas presence of respiratory disease had the lowest negative coefficients. The analysis of spirometric parameters depending on the coexisting respiratory disease showed that \% FVC in the subgroup of 15 miners diagnosed with respiratory disease was lower $(p<0,05)$, in comparison to healthy workers $(91,5 \pm 8,7$ versus $100,9 \pm 13,7$ in initial spirometry; $97,6 \pm 10,3$ versus $105,7 \pm 13,8$ after 10 years; and 98,0 $\pm 10,1$ versus 105,9 $\pm 17,2$ after 25 years of work).

3.3. The Analysis of Spirometric Indices Depending on Smoking. Among the confounding factors, the status of smoking had the greatest variability. Therefore, the analysis was extended by excluding smoking from the group of confounders and looking for existence of interaction between the workplace and smoking as independent factors.

The differences between smokers and nonsmokers were displayed at the start of employment. At that time, the mean period of smoking was $8,1 \pm 5,6$ years. The values of $F V_{1}$ and PEF, expressed as percentage of predicted normal values, were significantly $(p<0,05)$ lower in smokers than in nonsmokers $\left(\% \mathrm{FEV}_{1}: 102,9 \pm 15,2\right.$ and $105,6 \pm 14,9 ; \%$ PEF: $106,4 \pm 25,8$ and $110,1 \pm 26,9$, resp.). After 10 years of work, lower $\mathrm{FEV}_{1} / \mathrm{FVC}$ in smoking, in comparison to nonsmoking welders, was shown (Figure 1(c)). After the next 15 years, in general, spirometric parameters were also lower in smokers than in nonsmokers, and they were the lowest in the group of smoking welders (Figure 2).

The interactions between workplace and smoking in their effect on FVC, $\mathrm{FEV}_{1}, \% \mathrm{PEF}, \% \mathrm{FEF}_{25}, \mathrm{FEF}_{50}$, and $\% \mathrm{FEF}_{75}$ appeared after 20 years of work. Five years later, such interactions concerned only \% FVC; however, smoking independently influenced the $\mathrm{FEV}_{1} / \mathrm{FVC}$ ratio, \% $\mathrm{PEF}$, and \% $\mathrm{FEF}_{75}$ (Table 4).

\section{Discussion}

Commonly accepted indications to spirometry tests are diagnostic, epidemiological, and related to monitoring and to certification [21]. All these indications were present in underground copper miners exposed to nitric oxides and other mine gases. In this retrospective analysis of spirometric parameters, the impact of type of workplace on lung function over 25 years of observation was estimated.

4.1. Analysis of Spirometric Parameters in View of Bronchial Obstruction. An obstructive ventilatory disorder is a disproportionate reduction of maximal air flow from the lung in relation to the maximal volume that can be displaced from the lung. In the first spirometric test performed in 888 workers, the most important indicator of bronchial obstruction, the $\mathrm{FEV}_{1} / \mathrm{FVC}$ ratio, was normal according to recommendation of expert panel $[23,24]$, that is, higher than $70 \%$ of the predominant value. In recent years, it has been assumed that $\mathrm{FEV}_{1} / \mathrm{FVC}$ index equal to $70 \%$ does not reflect the real lower limit of the norm and it can be used only as a screening criterion or eligibility criterion for further diagnosis [25-27]. In 25 years of follow-up, it could be expected that a greater proportion of the population would have the $\mathrm{FEV}_{1} / \mathrm{FVC}$ ratio below 70\%, as the lower limit of normal (LLN) $\mathrm{FEV}_{1} / \mathrm{FVC}$ ratio would fall slightly with age. Therefore, it was better to refer obtained results to LLN, which includes age, than to fixed values. $\mathrm{FEV}_{1} / \mathrm{FVC}$ reduced below LLN was shown in the first spirometry in about $7 \%$ of subjects: in about $5 \%$ of these miners, the mean $\mathrm{FEV}_{1}$ was greater than LLN, and thus mild obstruction could be diagnosed, whereas, in $1 \%$ of miners, $\mathrm{FEV}_{1} / \mathrm{FVC}$ index and $\mathrm{FEV}_{1}$ \% were lower than LLN, leading to a diagnosis of moderate bronchial obstruction. Among these subjects, there were smokers (nearly 45\%) and men treated due to respiratory diseases. In relation to these data, the occurrence of bronchial obstruction in a few percent of miners appears to be only a small percentage of the total number of studied workers. However, it should be an indication to intense preventive activity, especially concerning smokers and miners diagnosed with respiratory disease.

After 10 years of employment, the number of miners with a reduced $\mathrm{FEV}_{1} / \mathrm{FVC}$ index was about twice lower (3\%) than in the first spirometry. After 20 years, bronchial obstruction could be diagnosed in $4,3 \%$ of miners and after 25 years 

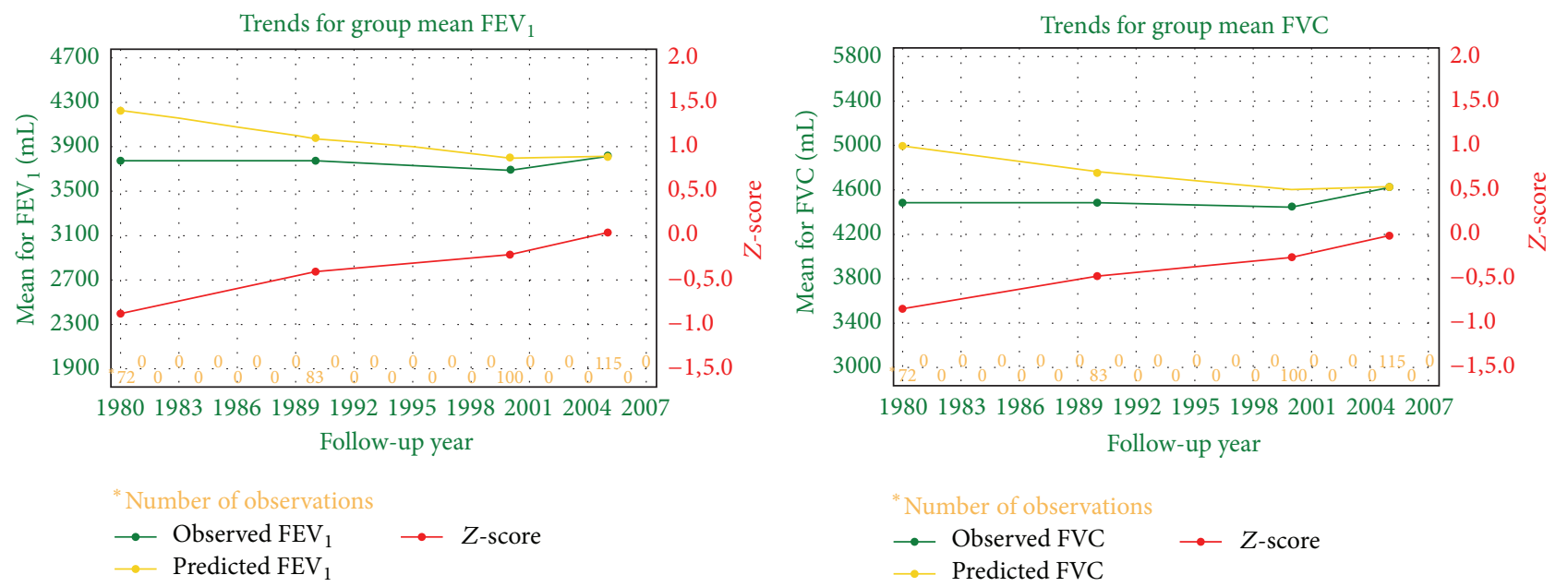

(a)
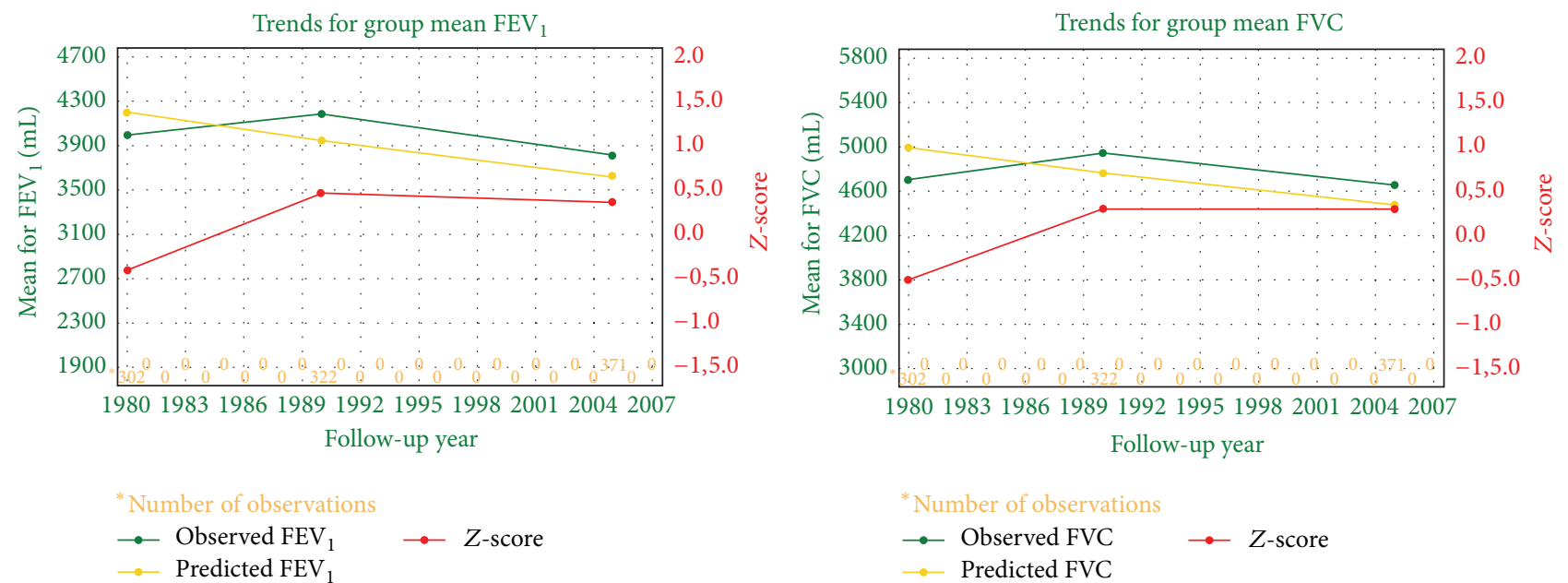

(b)
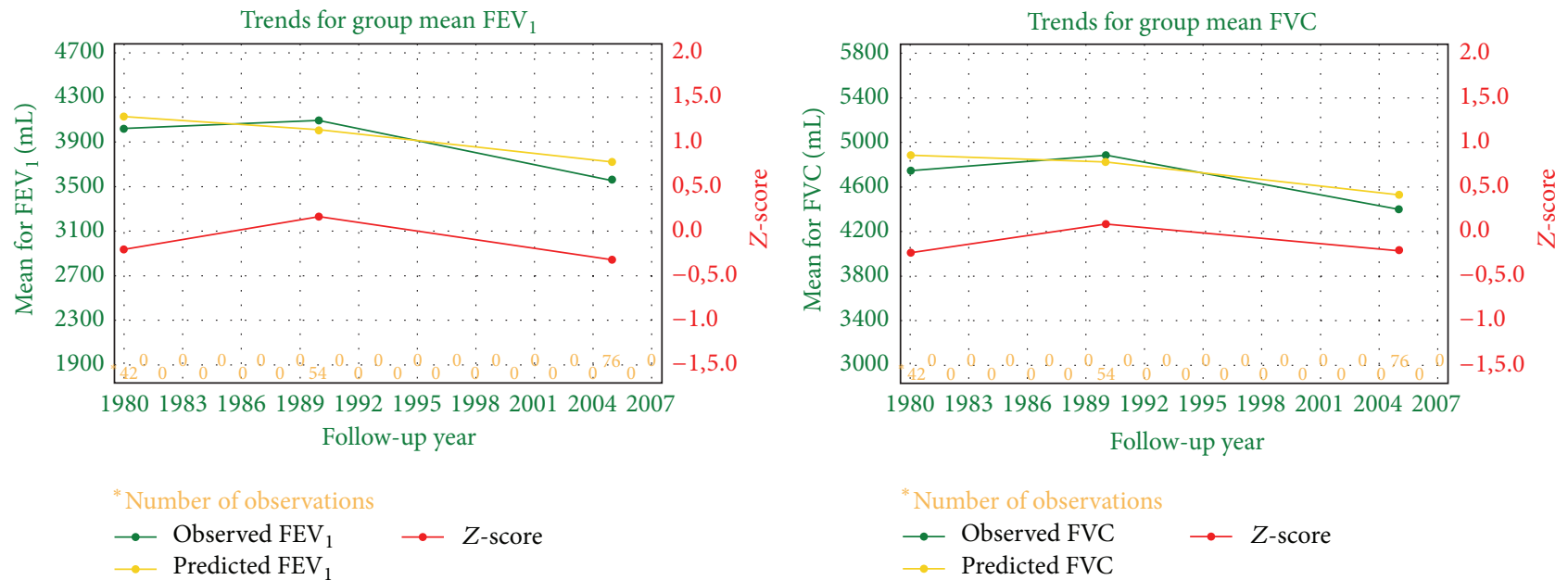

(c)

FIGURE 3: Trends in $\mathrm{FEV}_{1}$ and FVC over time in operators (a), others (b), and welders (c). On the basis of SPIROLA v3.0.2 software. The mean $\mathrm{FEV}_{1}$ chart shows group means for observed, predicted, and $Z$-score (standard deviation units from the predicted quantity) values. The same applies for FVC chart. The predicted values are derived from prediction equations that take into account age, height, sex, and race/ethnic background and are based on nationally representative healthy never-smokers. Irregular deviations of observed mean values from predicted values may be due to changes in measurement procedures or due to effects of occupational exposure or interventions. 
TABLE 3: Association between type of workplace and lung function after 10, 20, and 25 years of professional work. Multiple linear regressions adjusted for age, height, weight, BMI, smoking, and coexistence of respiratory disease.

\begin{tabular}{|c|c|c|c|c|}
\hline & & After 10 years & After 20 years & After 25 years \\
\hline Workplace & Level compared & $\begin{array}{c}\text { FVC } \beta \text {-coefficient } \\
\quad(95 \% \mathrm{CI})\end{array}$ & $\begin{array}{l}\text { FVC } \beta \text {-coefficient } \\
\quad(95 \% \mathrm{CI})\end{array}$ & $\begin{array}{l}\text { FVC } \beta \text {-coefficient } \\
\quad(95 \% \mathrm{CI})\end{array}$ \\
\hline \multirow{4}{*}{ Group } & Welders & 0 & 0 & 0 \\
\hline & Operators & $-0,06(-0,13$ to 0,01$)$ & $0,17(-0,18$ to 0,52$)$ & $-0,09(-0,21$ to 0,03$)$ \\
\hline & Others & $0.06(-0.01$ to 0.13$)$ & $-0,56(-0,90$ to $-0,22)$ & $0,21(-0,33$ to $-0,08)$ \\
\hline & $p$ value & 0.08 & 0,0022 & 0,0012 \\
\hline Workplace & Level compared & $\begin{array}{c}\mathrm{FEV}_{1} \beta \text {-coefficient }(95 \% \\
\mathrm{CI})\end{array}$ & $\begin{array}{l}\mathrm{FEV}_{1} \beta \text {-coefficient } \\
(95 \% \mathrm{CI})\end{array}$ & $\begin{array}{c}\mathrm{FEV}_{1} \beta \text {-coefficient }(95 \% \\
\mathrm{CI})\end{array}$ \\
\hline \multirow{4}{*}{ Group } & Welders & 0 & 0 & 0 \\
\hline & Operators & $-0,04(-0,12$ to 0,02$)$ & $0,23(-0,10$ to 0,57$)$ & $-0,04(-0,24$ to 0,008$)$ \\
\hline & Others & $0,05(-0,012$ to 0,13$)$ & $-0,63(-0,95$ to $-0,30)$ & $-0,12(-0,95$ to $-0,30)$ \\
\hline & $p$ value & 0,17 & 0,0004 & 0,0667 \\
\hline Workplace & Level compared & $\begin{array}{c}\mathrm{FEV}_{1} / \mathrm{FVC} \beta \text {-coefficient } \\
(95 \% \mathrm{CI})\end{array}$ & $\begin{array}{c}\mathrm{FEV}_{1} / \mathrm{FVC} \beta \text {-coefficient } \\
(95 \% \mathrm{CI})\end{array}$ & $\begin{array}{c}\mathrm{FEV}_{1} / \mathrm{FVC} \beta \text {-coefficient } \\
(95 \% \mathrm{CI})\end{array}$ \\
\hline \multirow{4}{*}{ Group } & Welders & 0 & 0 & 0 \\
\hline & Operators & $0,02(-0,06$ to 0,09$)$ & $0,19(-0,24$ to 0,64$)$ & $0,04(0,09$ to $-0,17)$ \\
\hline & Others & $-0,005(-0,08$ to 0,06$)$ & $-0,01(-0,43$ to 0,41$)$ & $0,09(-0,03$ to 0,22$)$ \\
\hline & $p$ value & 0,61 & 0,37 & 0,14 \\
\hline Workplace & Level compared & $\begin{array}{c}\text { PEF } \beta \text {-coefficient }(95 \% \\
\text { CI) }\end{array}$ & $\begin{array}{l}\text { PEF } \beta \text {-coefficient } \\
(95 \% \mathrm{CI})\end{array}$ & $\begin{array}{l}\text { PEF } \beta \text {-coefficient }(95 \% \\
\text { CI) }\end{array}$ \\
\hline \multirow{4}{*}{ Group } & Welders & 0 & 0 & 0 \\
\hline & Operators & $-0,001(-0,08$ to 0,07$)$ & $0,02(-0,36$ to 0,40$)$ & $0,004(-0,12$ to 0,13$)$ \\
\hline & Others & $0,04(-0,03$ to 0,11$)$ & $-0,31(-0,68$ to 0,40$)$ & $-0,13(-0,25$ to 0,007$)$ \\
\hline & $p$ value & 0,28 & 0,08 & 0,0379 \\
\hline Workplace & Level compared & $\begin{array}{c}\mathrm{FEV}_{25} \beta \text {-coefficient }(95 \% \\
\mathrm{CI})\end{array}$ & $\begin{array}{c}\mathrm{FEV}_{25} \beta \text {-coefficient }(95 \% \\
\mathrm{CI})\end{array}$ & $\begin{array}{c}\mathrm{FEV}_{25} \beta \text {-coefficient }(95 \% \\
\mathrm{CI})\end{array}$ \\
\hline \multirow{4}{*}{ Group } & Welders & 0 & 0 & 0 \\
\hline & Operators & $0,04(-0,03$ to 0,11$)$ & $0,02(-0,40$ to 0,45$)$ & $-0,02(-0,15$ to 0,10$)$ \\
\hline & Others & $-0,06(-0,13$ to 0,01 & $-0,24(-0,66$ to 0,16$)$ & $-0,07(-0,20$ to 0,05$)$ \\
\hline & $p$ value & 0,09 & 0,22 & 0,23 \\
\hline Workplace & Level compared & $\begin{array}{c}\mathrm{FEV}_{25-75} \beta \text {-coefficient } \\
(95 \% \mathrm{CI})\end{array}$ & $\begin{array}{c}\mathrm{FEV}_{25-75} \beta \text {-coefficient } \\
(95 \% \mathrm{CI})\end{array}$ & $\begin{array}{c}\mathrm{FEV}_{25-75} \beta \text {-coefficient } \\
(95 \% \mathrm{CI})\end{array}$ \\
\hline \multirow{4}{*}{ Group } & Welders & 0 & 0 & 0 \\
\hline & Operators & $-0,01(-0,09$ to 0,06$)$ & $0,34(-0,06$ to 0,75$)$ & $0,06(-0,06$ to 0,19$)$ \\
\hline & Others & $0,02(-0,05$ to 0,09$)$ & $-0,44(-0,83$ to $-0,05)$ & $-0,01(-0,14$ to 0,11$)$ \\
\hline & $p$ value & 0,58 & 0,0268 & 0,29 \\
\hline Workplace & Level compared & $\begin{array}{c}\mathrm{FEV}_{50} \beta \text {-coefficient }(95 \% \\
\mathrm{CI})\end{array}$ & $\begin{array}{c}\mathrm{FEV}_{50} \beta \text {-coefficient }(95 \% \\
\mathrm{CI})\end{array}$ & $\begin{array}{c}\mathrm{FEV}_{50} \beta \text {-coefficient }(95 \% \\
\mathrm{CI})\end{array}$ \\
\hline \multirow{4}{*}{ Group } & Welders & 0 & 0 & 0 \\
\hline & Operators & $-0,02(-0,09$ to 0,05$)$ & $0,39(0,009$ to 0,78$)$ & $0,01(-0,11$ to 0,14$)$ \\
\hline & Others & $0,03(-0,04$ to 0,10$)$ & $-0,41(-0,79$ to $-0,04)$ & $0,01(-0,12$ to 0,14$)$ \\
\hline & $p$ value & 0,49 & 0,0282 & 0,83 \\
\hline Workplace & Level compared & $\begin{array}{c}\mathrm{FEV}_{75} \beta \text {-coefficient }(95 \% \\
\mathrm{CI})\end{array}$ & $\begin{array}{c}\mathrm{FEV}_{75} \beta \text {-coefficient }(95 \% \\
\mathrm{CI})\end{array}$ & $\begin{array}{c}\mathrm{FEV}_{75} \beta \text {-coefficient }(95 \% \\
\mathrm{CI})\end{array}$ \\
\hline \multirow{4}{*}{ Group } & Welders & 0 & 0 & 0 \\
\hline & Operators & $-0,03(-0,11$ to 0,04$)$ & $0,04(-0,37$ to 0,46$)$ & $0,07(-0,05$ to 0,20$)$ \\
\hline & Others & $0,07(0,001$ to 0,15$)$ & $0,03(-0,36$ to 0,44$)$ & $0,002(-0,12$ to 0,13$)$ \\
\hline & $p$ value & 0,44 & 0,83 & 0,23 \\
\hline
\end{tabular}

CI: confidence interval; $p$ values in bold indicate statistical significance. 


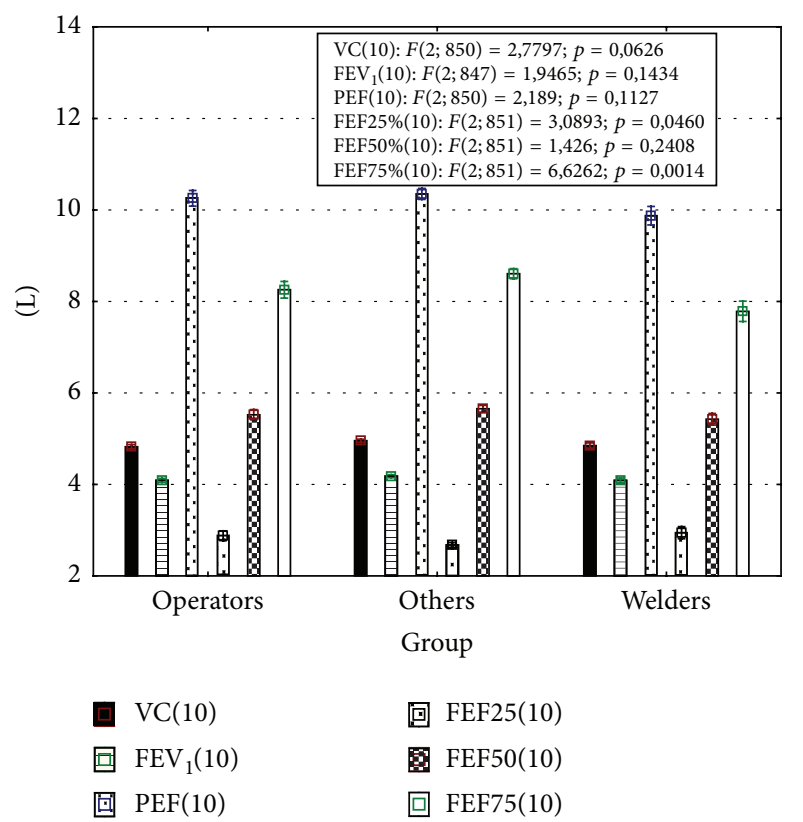

(a)

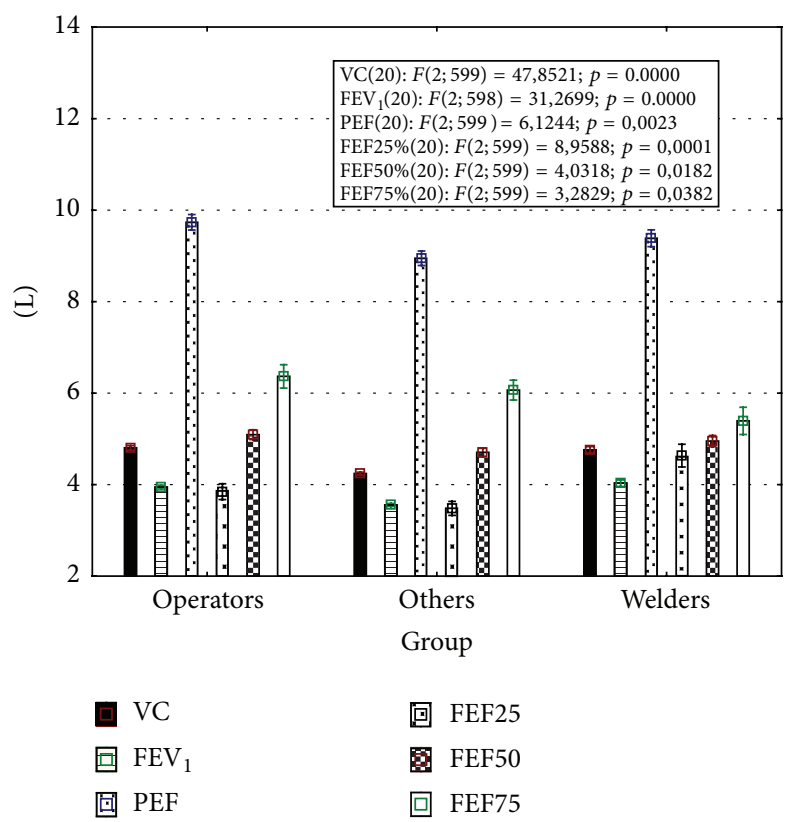

(b)
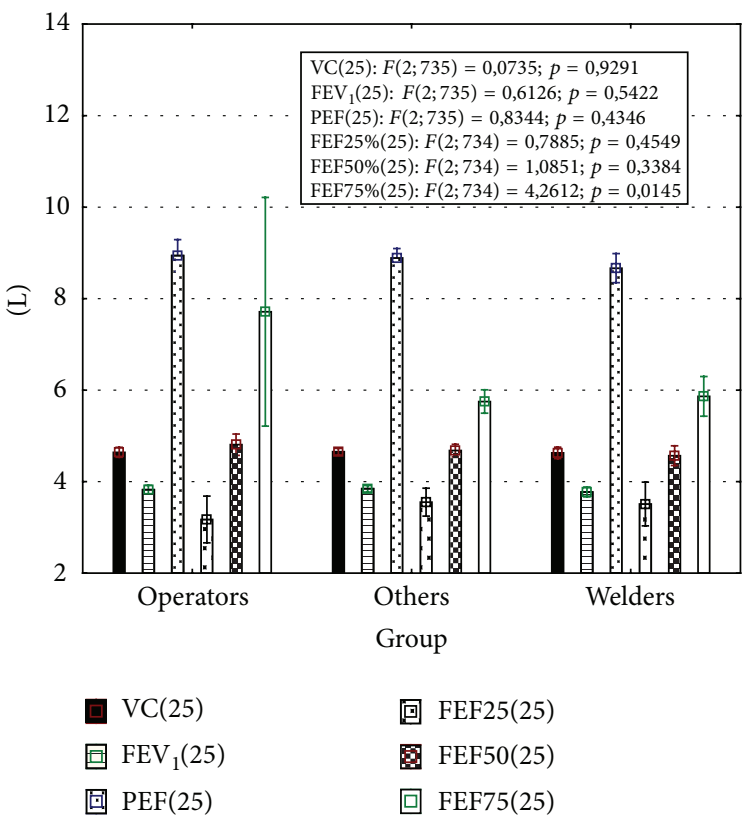

(c)

FIgURE 4: Absolute spirometric indices after 10 (a), 20 (b), and 25 (c) years of work. Results are presented as mean \pm standard error. In frames results of ANOVA $F$-test were presented. This test was used to assess whether any of the workplaces is on average superior, or inferior, to the others versus the null hypothesis that all three workplaces yield the same mean response in lung function.

in about $4 \%$. A decreased number of men with low lung function during 25 years of observation, associated with small number of miners diagnosed with a respiratory disease, could be a consequence of the decreased percentage of smokers in the studied population. On the other hand, miners with a decreased $\mathrm{FEV}_{1} / \mathrm{FVC}$ index displayed gradual decrease in $\% \mathrm{FEF}_{25}$ and $\% \mathrm{FEF}_{75}$, which indicates the impairment not only of central, but also of peripheral bronchial function. It is documented that obstructive changes may be manifested as a reduction of air flow in the final phase of exhalation, which results in the maximum expiratory flow disturbances, especially at $\mathrm{FEF}_{25-75}, \mathrm{FEF}_{50}$, and $\mathrm{FEF}_{75}$. These changes are nonspecific, and the variance of these indicators in a healthy population is very large; hence, the reduction does not constitute a basis for diagnosis of pathology in case other results are correct [26]. Many somatic parameters, as gradual body mass increase, observed also in our study, can influence these spirometric changes [28]. Moreover, progressive age 
TABLE 4: The effect of workplace and smoking and interaction between these factors in their effect on spirometric parameters in copper miners after 10, 20, and 25 years of work.

\begin{tabular}{|c|c|c|c|c|c|c|}
\hline \multirow{2}{*}{ Effect } & \multicolumn{2}{|c|}{ After 10 years } & \multicolumn{2}{|c|}{ After 20 years } & \multicolumn{2}{|c|}{ After 25 years } \\
\hline & $F$ & $p$ & $F$ & $p$ & $F$ & $p$ \\
\hline & \multicolumn{2}{|c|}{$\% \mathrm{FVC}$} & \multicolumn{2}{|c|}{ FVC } & \multicolumn{2}{|c|}{ FVC } \\
\hline Workplace & 0,72 & 0,4859 & 5,85 & 0,0075 & 8,32 & 0,0003 \\
\hline Smoking & 1,77 & 0,1840 & 2,04 & 0,1633 & 0,04 & 0,8376 \\
\hline \multirow[t]{2}{*}{ Workplace $*$ smoking } & 0,30 & 0,7391 & 4,22 & 0,0248 & 1,90 & 0,0089 \\
\hline & \multicolumn{2}{|c|}{$\% \mathrm{FEV}_{1}$} & \multicolumn{2}{|c|}{$\mathrm{FEV}_{1}$} & \multicolumn{2}{|c|}{$\% \mathrm{FEV}_{1}$} \\
\hline Workplace & 0,91 & 0,4017 & 8,02 & 0,0017 & 0,83 & 0,4331 \\
\hline Smoking & 0,15 & 0,6957 & 5,03 & 0,0328 & 1,97 & 0,1611 \\
\hline \multirow[t]{2}{*}{ Workplace $*$ smoking } & 0,10 & 0,9088 & 5,02 & 0,0136 & 0,52 & 0,5934 \\
\hline & \multicolumn{2}{|c|}{$\mathrm{FEV}_{1} / \mathrm{FVC}$} & \multicolumn{2}{|c|}{$\mathrm{FEV}_{1} / \mathrm{FVC}$} & \multicolumn{2}{|c|}{$\mathrm{FEV}_{1} / \mathrm{FVC}$} \\
\hline Workplace & 0,39 & 0,6753 & 0,17 & 0,8385 & 2,36 & 0,0964 \\
\hline Smoking & 0,79 & 0,3730 & 1,40 & 0,2463 & 4,32 & 0,0387 \\
\hline \multirow[t]{2}{*}{ Workplace $*$ smoking } & 1,10 & 0,3339 & 0,29 & 0,7499 & 1,24 & 0,2901 \\
\hline & \multicolumn{2}{|c|}{$\% \mathrm{PEF}$} & \multicolumn{2}{|c|}{$\%$ PEF } & \multicolumn{2}{|c|}{$\% \mathrm{PEF}$} \\
\hline Workplace & 1,62 & 0,1972 & 1,11 & 0,3431 & 1,94 & 0,1457 \\
\hline Smoking & 0,02 & 0,8768 & 0,26 & 0,6100 & 6,67 & 0,0102 \\
\hline \multirow[t]{2}{*}{ Workplace $*$ smoking } & 0,50 & 0,6033 & 3,70 & 0,0373 & 1,76 & 0,1736 \\
\hline & \multicolumn{2}{|c|}{$\% \mathrm{FEF}_{25}$} & \multicolumn{2}{|c|}{$\% \mathrm{FEF}_{25}$} & \multicolumn{2}{|c|}{$\% \mathrm{FEF}_{25}$} \\
\hline Workplace & 0,65 & 0,5220 & 1,41 & 0,2593 & 0,36 & 0,6958 \\
\hline Smoking & 1,72 & 0,1900 & 4,09 & 0,0525 & 3,33 & 0,0691 \\
\hline \multirow[t]{2}{*}{ Workplace $*$ smoking } & 0,28 & 0,7534 & 3,44 & 0,0460 & 0,75 & 0,4725 \\
\hline & \multicolumn{2}{|c|}{$\% \mathrm{FEF}_{50}$} & \multicolumn{2}{|c|}{$\mathrm{FEF}_{50}$} & \multicolumn{2}{|c|}{$\% \mathrm{FEF}_{50}$} \\
\hline Workplace & 0,44 & 0,6382 & 3,38 & 0,0481 & 0,33 & 0,7188 \\
\hline Smoking & 0,13 & 0,7133 & 2,73 & 0,1096 & 2,81 & 0,0944 \\
\hline \multirow[t]{2}{*}{ Workplace $*$ smoking } & 0,76 & 0,4638 & 3,84 & 0,0334 & 0,64 & 0,5275 \\
\hline & \multicolumn{2}{|c|}{$\% \mathrm{FEF}_{75}$} & \multicolumn{2}{|c|}{$\% \mathrm{FEF}_{75}$} & \multicolumn{2}{|c|}{$\% \mathrm{FEF}_{75}$} \\
\hline Workplace & 0,62 & 0,5362 & 0,39 & 0,6775 & 0,95 & 0,3878 \\
\hline Smoking & 0,29 & 0,5899 & 1,67 & 0,2067 & 4,48 & 0,0350 \\
\hline Workplace $*$ smoking & 1,74 & 0,1750 & 3,35 & 0,0494 & 0,54 & 0,5819 \\
\hline
\end{tabular}

Spreadsheet of two-way analysis of variance; one-dimensional tests of significance. $F$ : $F$-test value for the respective effects; $p$ : the probability level of $p$; values indicated in bold are statistically significant.

of workers impacted, alongside the length of employment period, lung function, as the negative correlation between age and $\mathrm{FEV}_{1} / \mathrm{FVC}$ ratio $(p<0,001)$ was shown in our study, similarly as in others [29].

Additionally, in comparison to the first spirometry, spirometric tests conducted after 25 years of the employment showed a significant decrease in the relative peak expiratory flow. The reduction of PEF is a characteristic form of bronchial obstruction in the course of chronic bronchitis or asthma [30], whereas in this study allergic disease was diagnosed only in seven workers. On the other hand, \% PEF changes did not exceed $10 \%$ in relation to initial values. PEF is known as a good index of the bronchi patency but is subject to oscillation; that is, in healthy men, even a short-term (i.e., twenty-four hours) fluctuation of PEF reaches $15 \%$.

4.2. Assessment of Spirometric Indices in View of Restriction. In the absence of the measurement of total lung capacity, it is acceptable to classify the degree of restriction on the basis of the FVC; however, it is not synonymous with a diagnosis of restriction. Correct FVC values do not exclude the possibility of functional disorders concerning mechanical properties or diffusion across the alveolar-capillary barrier [23, 24]. Our analysis showed a reduced \% FVC below the 5th percentile of FVC only in $4.4 \%$ of workers. Reduction in FVC\% was accompanied by a slight (statistically nonsignificant) decrease in $\mathrm{FEV}_{1} / \mathrm{FVC}$ ratio, so the occurrence of restrictive changes in this group could be suspected. However, taking into account the simultaneous reduction in $\mathrm{FEV}_{1}$ (to value less than LLN), the number of people with suspected restrictive changes decreased to $9(1.0 \%)$. After 10 years of work, the percentage of such workers was $0.6 \%$, after 20 years, $1.2 \%$, and after 25 years, $2.9 \%$. Regarding the entire pool of workers, the problem of restrictive changes seems to be important only individually.

4.3. The Impact of the Type of Workplace on the Lung Function. During 25 years of observation, the decrease in $\mathrm{FEV}_{1} / \mathrm{FVC}$ ratio and $\mathrm{FEV}_{1}$ was observed in all groups of copper miners. 
Absolute and relative decline in $\mathrm{FEV}_{1}$ from first to last measurement were similar in operators, welders, and other miners and were much less than $40 \mathrm{~mL} /$ year (referential data). Nonetheless, the mean group slope for decline of $\mathrm{FEV}_{1}$ in welders $(-21 \mathrm{~mL} /$ year $)$ was greater in comparison to operators $(-1 \mathrm{~mL} /$ year $)$ or other workers $(-8 \mathrm{~mL} /$ year $)$. The rate of decline $<30 \mathrm{~mL} /$ year, established over 5 or more years, is not associated with increased morbidity and mortality regardless of the level of lung function [31]. Also, the absolute and relative slopes for $\mathrm{FEV}_{1}$ were similar in all studied groups of miners and amounted to less than 15\% in longterm observation. The American College of Occupational and Environmental Medicine [32] recommends a longitudinal limit based on annual acceptable decline of $15 \%$, which is comparable to LLD, using within-person variation of $6 \%$. Trends in $\mathrm{FEV}_{1}$ and $\mathrm{FVC}$, showing prognosis for subsequent years, were also similar in groups of operators, welders, and other miners. Thus, respiratory function assessed on the basis of the mean slope and within-person variation for $\mathrm{FEV}_{1}$ (FVC) in studied groups was similar in miners working underground at various workplaces. Impaired lung function, assessed on the basis of excessive FEV $_{1}$ (FVC) decline, occurred in such a small number of miners that it was difficult to state whether there was increased predisposition of miners employed at any particular workplace.

Simultaneously, using the multiple linear regression model in cross-sectional analysis, the association between workplace type and lung function, independent of the impact of age, height, weight, BMI, smoking, and coexisting respiratory disease, was shown. This association appeared after 20 years of underground work. However, differences in spirometric indices between welders and other miners were apparent as early as after 10 years of work. At that time, welders displayed a slightly lower \% PEF and a significantly lower $\% \mathrm{FEF}_{75}$ than operators or other employees. These results can announce obstructive disturbances rather than restrictive ones. Also, Fidan et al. observed a decrease in parameters of forced expiratory flow, including $\mathrm{FEF}_{75}$, and, simultaneously, a higher risk for chronic bronchitis in welders in comparison to a control group [33]. In case of welders working underground, apart from the impact of mine gases containing nitrogen oxides, an additional source of emissions of these gases, as well as harmful metal oxides particles, is welding fumes [34]. This complex exposure may explain the occurrence of early obstructive changes in welders. In our analysis, lung function disorders in welders were dependent upon the time of exposure; they first appeared after 10 years of employment and expanded in the following measurements to other indices, including significant changes in $\mathrm{FEV}_{1}$. Also, other authors indicated a reduction in $\mathrm{FEV}_{1}$ or PEF in welders exposed to welding gases for more than 9 years, whereas workers with exposure of less than 5 years did not show any significant changes [35]. Haluza et al. observed a decrease of pulmonary function during the period of occupational exposure to welding fumes [36]. Among British coal miners, the loss of $\mathrm{FEV}_{1}$ over 11 years was related to occupational exposure and to smoking [12].

After 20 and 25 years of work, association between workplace type and lung function was shown as dependence of absolute spirometric parameters on type of job in a linear regression model. These parameters included indicators of not only obstruction, but also restriction. In comparison to welders or operators, other workers displayed lower lung function. These results can be a consequence of long-term exposure to mine gases containing nitric oxides as well as other gases toxic for the respiratory system, that is, hydrogen sulfide. The group of "other" workers included hewers who are the most exposed workers to dust and gases among miners.

In general, during the 25 years of this follow-up observation, the exposure of miners to nitrogen oxides, especially nitrogen dioxide, was low. The time weighted average (TWA) concentrations for nitric oxides ranged from subdetectable (most often) up to $2,02 \mathrm{mg} / \mathrm{m}^{3}$ (rarely in 2001-2009), which is below respective Maximum Allowable Concentrations (MAC). The short-term exposure concentration (STEL) for nitric dioxide in some cases exceeded safe levels and in some measurements in 2007 reached $3,96 \mathrm{mg} / \mathrm{m}^{3}$. In 2002, MAC and STEL values were corrected according to the SCOEL recommendation (at present, the MAC amounts to $0,6 \mathrm{mg} / \mathrm{m}^{3}$ for $\mathrm{NO}_{2}$ and $3,0 \mathrm{mg} / \mathrm{m}^{3}$ for $\mathrm{NO}$, whereas the STEL for $\mathrm{NO}_{2}$ is $1,5 \mathrm{mg} / \mathrm{m}^{3}$ and for $\mathrm{NO}$ is $7,5 \mathrm{mg} / \mathrm{m}^{3}$ ) [14].

In the analysis, the impact of confounding factors on lung function must not be omitted. In each group, the negative effect of age was typical $[22,29]$, while the effect of height and BMI in relation to spirometric parameters was similar to the one observed by other authors in normalweight subjects [37-39]. In most miners, the measured BMI gradually increased over 25 years of observation; however, in most cases, it increased up to value lower than $30,0 \mathrm{~kg} / \mathrm{m}^{2}$. It may explain the positive correlation observed between BMI and FVC. Also, Chen et al. observed that, in subjects with normal weight, BMI was positively associated with FVC and $\mathrm{FEV}_{1}$ [40].

Another reason for the moderate increase in FVC could be the decrease in number of smokers during 25 years of work. On the other hand, smoking remains the single most important cause of obstruction [41]. In our study, differences in obstructive indices between smokers and nonsmokers appeared as early as in the first spirometry. The mean period of smoking was then about eight years. In comparison to nonsmokers, smokers displayed a significant decrease in $\% \mathrm{FEV}_{1}$ and \% $\mathrm{PEF}$, recognized as sensitive indicators of reduced air flow through constricted bronchi [42]. As might be predicted, over years of smoking, the differences between smokers and nonsmokers expanded to other spirometric indices, and, after 10 years of work, a significant lower $\mathrm{FEV}_{1} / \mathrm{FVC}$ index in smokers was shown. The mean age of smoking workers was then $38,5 \pm 3,61$ years. Throughout the 25 years of the study, the biggest decline of lung function was observed in smoking welders (Figures 1-2), as well as in other studies $[43,44]$.

According to the National Lung Health Education Program, primary care should perform spirometry tests on smoking patients aged 45 years or older in order to detect airways obstruction and aid smoking cessation efforts [45]. These recommendations were developed based on the 
research conducted over 20 years, which summarizes the results of spirometry, smoking status, and symptoms of respiratory disease in the US population. Air flow obstruction was defined on the basis of the abnormal value of $\mathrm{FEV}_{1} / \mathrm{FEV}_{6}$ and $\mathrm{FEV}_{1}$. Such changes in spirometry in smokers were revealed mainly in subjects aged over 45 years, and only 5 percent of smokers aged less than 45 years showed abnormal ventilation. Our analysis showed the age of smokers with worse lung function to be lower by a few years. This difference may result from specificity of miners work conditions, including underground work in exposure to mine gases and dust. Of much significance could be the existence of an interaction between workplace and smoking, confirmed by this analysis in workers working for 20 years or more. On the other hand, our results confirm the validity of European societies' recommendations to evaluate the effects of smoking in male smokers who are under 45 years of age and also the relevance of the National Program of Early COPD Detection [46], advising to evaluate the effects of smoking in smokers who are under 40 years old.

4.4. Advantages and Disadvantages. An advantage of this study is the diversification of the professional group of copper miners, which allowed an evaluation of the association between type of workplace and lung function in crosssectional analysis. The groups of miners were numerous; moreover, miners were monitored over a long period of 25 years, which allowed the assessment of the relationship between workplace and lung function in this longitudinal observation.

One limitation of this analysis is the lack of a control or low to no exposure group for comparison. The disadvantage of the study may be a various number of miners in successive stages of observation. This has resulted in a reduced number of miners investigated in next stages of this evaluation, but especially between 1998 and 2000. It has been reported that results from longitudinal study of workers may be biased if there is a systematic exodus of certain types of workers between the surveys [12]. Other survey bias that can significantly influence the results, that is, a significant increase in lung function drops at a particular testing site or during a particular testing time period, has been described [47]. In this study, data for miners who attended the first survey were not separated into those collected from subjects who also attended the later survey (stayers) and those taken from subjects who did not (leavers), as in many individual cases results of only one test (usually the test performed after 20 years of start of employment) were unavailable. However, a variable number of available spirometry results could affect the accuracy of analysis. Assessment of lung function decline is affected also by factors such as spirometry tests' technical quality, test variability, testing frequency, duration of followup, and definition of excessive decline [26]. The precision of longitudinal measurements has been often determined by the magnitude of the within-person variation. In this study, using SPIROLA program, the authors monitored retrospectively the magnitude of the within-person relative standard deviation $s_{r}$ for $\mathrm{FEV}_{1}$ and FVC in groups of workers employed at various workplaces in the same copper mine. In all studied groups, $s_{r}$ was lower than referential value, which is $4 \% . Z$ score values, presented graphically as charts of trends for $\mathrm{FEV}_{1}$ and FVC, were similar in all groups. Nonetheless, although the assessment of respiratory outcomes followed an international standardized protocol, the $\mathrm{FEV}_{1}$ (FVC) excessive variance in follow-up study was relatively high.

In our analysis, the lung dysfunction was defined as $\mathrm{FEV}_{1}, \mathrm{FVC}$, or $\mathrm{FEV}_{1} / \mathrm{FVC}$ ratio lowered below the LLN (5th percentile in the reference population, sex, age, and height matched). Although this method is burdened with a 5\% risk of false positive results, such a risk is generally acceptable. This type of presentation is regarded as the gold standard in epidemiological studies and recommended by scientific societies such as ATS, ERS, and BTS [26].

\section{Conclusions}

In long-term follow-up, lung function in copper miners working underground at various workplaces was similar. Nevertheless, in cross-sectional analysis, a significant association between the type of job and lung function appeared after 20 years of work. Additionally, as soon as after 10 years of work, discrete obstructive type disturbances appeared in welders. This may be associated with smoking (the proportion of smokers in this group of miners compared with other groups was higher). Also, welding gases containing nitrogen oxides can affect airway flow in these workers, especially as, after 20 years of work, interactions between workplace and smoking were found. Thus, it should be emphasized that smoking welders should be referred to early clinical diagnostics.

\author{
Abbreviations \\ FVC: $\quad$ Forced vital capacity \\ $\mathrm{FEV}_{1}$ : $\quad$ Forced expiratory volume in the first \\ second of forced exhalation \\ $\mathrm{FEF}_{25 \%}$ : $\quad$ Forced expiratory flow at $25 \%$ of expired \\ forced vital capacity \\ $\mathrm{FEF}_{50 \%}$ : $\quad$ Forced expiratory flow at $50 \%$ of expired \\ forced vital capacity \\ $\mathrm{FEF}_{75 \%}$ : $\quad$ Forced expiratory flow at $75 \%$ of expired \\ forced vital capacity \\ $\mathrm{FEF}_{25 \%-75 \%}$ : Forced expiratory volume between 25\% \\ and $75 \%$ of FVC \\ PEF: $\quad$ Peak expiratory flow.
}

\section{Competing Interests}

The authors declare that they have no competing interests.

\section{Authors' Contributions}

Anna Skoczyńska developed the concept and results of the research, and he wrote the main part of the paper. Leszek Gruszczyński has collected and developed the results of nitrogen oxides measurements at the workplaces. Anna Wojakowska participated in the design of the study and performed the statistical analysis. Marek Ścieszka has developed 
a database for statistical calculations and participated in the design of the study. Barbara Turczyn participated in the design of the study and helped to draft the paper. Edward Schmidt participated in the sequence alignment. All authors read and approved the final paper.

\section{Acknowledgments}

This research was supported by the Copper Health Center SA, Lubin, Poland, on the basis of an agreement between the Copper Health Center SA and Wrocław Medical University, Wrocław, Poland (no. 2178/2013-832/2013).

\section{References}

[1] P. J. Bamnes and M. G. Belvisi, "Nitric oxide and lung disease," Thorax, vol. 48, no. 10, pp. 1034-1043, 1993.

[2] B. Gaston, J. M. Drazen, J. Loscalzo, and J. S. Stamler, "The biology of nitrogen oxides in the airways," American Journal of Respiratory and Critical Care Medicine, vol. 149, no. 2, pp. 538551, 1994.

[3] P. J. Barnes, R. A. Dweik, A. F. Gelb et al., "Exhaled nitric oxide in pulmonary diseases: a comprehensive review," Chest, vol. 138, no. 3, pp. 682-692, 2010.

[4] R. A. Dweik, D. Laskowski, H. M. Abu-Soud et al., "Nitric oxide synthesis in the lung. Regulation by oxygen through a kinetic mechanism," The Journal of Clinical Investigation, vol. 101, no. 3, pp. 660-666, 1998.

[5] R. A. Dweik, D. Laskowski, M. Özkan, C. Farver, and S. C. Erzurum, "High levels of exhaled nitric oxide (NO) and NO synthase III expression in lesional smooth muscle in lymphangioleiomyomatosis," American Journal of Respiratory Cell and Molecular Biology, vol. 24, no. 4, pp. 414-418, 2001.

[6] R. A. Dweik, "Pulmonary hypertension and the search for the selective pulmonary vasodilator," The Lancet, vol. 360, no. 9337, pp. 886-887, 2002.

[7] F. L. M. Ricciardolo, P. J. Sterk, B. Gaston, and G. Folkerts, "Nitric oxide in health and disease of the respiratory system," Physiological Reviews, vol. 84, no. 3, pp. 731-765, 2004.

[8] S. L. Kao, E. S. Yap, S. M. Khoo, T. K. Lim, A. Mukhopadhyay, and S. T. L. Teo, "Acute lung injury after inhalation of nitric acid," European Journal of Emergency Medicine, vol. 15, no. 6, pp. 348350, 2008.

[9] T. K. Jayalakshmi, S. Shah, I. Lobo, A. Uppe, and A. Mehta, "Acute lung injury following exposure to nitric acid," Lung India, vol. 26, no. 4, pp. 149-151, 2009.

[10] T. T. Mensinga, G. J. A. Speijers, and J. Meulenbelt, "Health implications of exposure to environmental nitrogenous compounds," Toxicological Reviews, vol. 22, no. 1, pp. 41-51, 2003.

[11] M. Jacobsen, T. A. Smith, J. F. Hurley, A. Robertson, and R. Roscrow, "Respiratory infections in coal miners exposed to nitric oxides," Research Report (Health Effects Institute), vol. 18, pp. 1-56, 1988.

[12] M. D. Attfield, "Longitudinal decline in $\mathrm{FEV}_{1}$ in United States coalminers," Thorax, vol. 40, no. 2, pp. 132-137, 1985.

[13] M. B. Rice, P. L. Ljungman, E. H. Wilker et al., "Short-term exposure to air pollution and lung function in the framingham heart study," American Journal of Respiratory and Critical Care Medicine, vol. 188, no. 11, pp. 1351-1357, 2013.
[14] M. Kupczewska-Dobecka and S. Czerczak, "Hygienic standards of the occupational air quality established by the Experts Chemical Agents," Medycyna Pracy, vol. 55, pp. 7-12, 2002.

[15] D. Dahmann, P. Morfeld, C. Monz, B. Noll, and F. Gast, "Exposure assessment for nitrogen oxides and carbon monoxide in German hard coal mining," International Archives of Occupational and Environmental Health, vol. 82, no. 10, pp. 1267-1279, 2009.

[16] A. D. Bugarski, E. G. Cauda, S. J. Janisko, J. A. Hummer, and L. D. Patts, "Aerosols emitted in underground mine air by diesel engine fueled with biodiesel," Journal of the Air and Waste Management Association, vol. 60, no. 2, pp. 237-244, 2010.

[17] J. B. Coble, P. A. Stewart, R. Vermeulen et al., "The diesel exhaust in miners study: II. Exposure monitoring surveys and development of exposure groups," Annals of Occupational Hygiene, vol. 54, no. 7, pp. 747-761, 2010.

[18] American Thoracic Society, Standardization of Spirometry: A Summary of Recommendations from the American Thoracic Society, American Thoracic Society, 1988.

[19] European Respiratory Society, "Standardized lung function testing. Official statement of the European Respiratory Society," The European Respiratory Journal, Supplement, vol. 16, pp. 1-100, 1993.

[20] V. Brusasco, R. Crapo, and G. Viegi, "ATS/ERS task force: standardization of lung function testing," European Respiratory Journal, vol. 26, no. 5, pp. 948-968, 2005.

[21] M. R. Miller, J. Hankinson, V. Brusasco et al., "Standardisation of spirometry," European Respiratory Journal, vol. 26, no. 2, pp. 319-338, 2005

[22] C. A. Redlich, S. M. Tarlo, J. L. Hankinson et al., "Reply: spirometry in the occupational setting," American Journal of Respiratory and Critical Care Medicine, vol. 190, no. 3, pp. 353354, 2014.

[23] National Asthma Education and Prevention Program (NAEPP), Expert Panel Report 3: Guidelines for the Diagnosis and Management of Asthma, National Heart Lung and Blood Institute, 2007.

[24] British Thoracic Society, British Guideline on the Management of Asthma, British Thoracic Society, 2008.

[25] E. Falaschetti, J. Laiho, P. Primatesta, and S. Purdon, "Prediction equations for normal and low lung function from the health survey for England," European Respiratory Journal, vol. 23, no. 3, pp. 456-463, 2004.

[26] R. Pellegrino, G. Viegi, V. Brusasco et al., "Interpretative strategies for lung function tests," European Respiratory Journal, vol. 26, no. 5, pp. 948-968, 2005.

[27] W. Tomalak, A. Antczak, P. Boros et al., "Recommendations of the Polish Society pneumological on spirometry," Pneumologia i Alergologia Polska, vol. 72, pp. 7-9, 2004.

[28] T. Ignasiak, Z. Ignasiak, E. Ziółkowska-Łajp, K. Rozek, T. Sławińska, and A. Skrzek, "Evaluation of somatic and functional parameters of cardiovascular and respiratory systems in rural women in Poland," Anthropological Review, vol. 75, no. 2, pp. 107-116, 2012.

[29] M. Czajkowska-Malinowska, W. Tomalak, and J. Radliński, "Quality of spirometry in the elderly," Pneumonologia i Alergologia Polska, vol. 81, no. 6, pp. 511-517, 2013.

[30] J. van Schoor, G. F. Joos, and R. A. Pauwels, "Indirect bronchial hyperresponsiveness in asthma: mechanisms, pharmacology and implications for clinical research," European Respiratory Journal, vol. 16, no. 3, pp. 514-533, 2000. 
[31] P. Baughman, J. L. Marott, P. Lange et al., "Combined effect of lung function level and decline increases morbidity and mortality risks," European Journal of Epidemiology, vol. 27, no. 12, pp. 933-943, 2012.

[32] M. C. Townsend, "ACOEM position statement. Spirometry in the occupational setting. American College of Occupational and Environmental Medicine," Journal of Occupational and Environmental Medicine, vol. 42, no. 3, pp. 228-245, 2000.

[33] F. Fidan, M. Ünlü, T. Köken et al., "Oxidant-antioxidant status and pulmonary function in welding workers," Journal of Occupational Health, vol. 47, no. 4, pp. 286-292, 2005.

[34] W. Matczak and J. Gromiec, "Occupational exposure to gases emitted in mild and stainless steel welding," Medycyna Pracy, vol. 52, no. 6, pp. 423-436, 2001.

[35] S. A. Meo, M. Abdul Azeem, and M. M. F. Subhan, "Lung function in Pakistani welding workers," Journal of Occupational and Environmental Medicine, vol. 45, no. 10, pp. 1068-1073, 2003.

[36] D. Haluza, H. Moshammer, and K. Hochgatterer, "Dust is in the air. Part II: effects of occupational exposure to welding fumes on lung function in a 9-year study," Lung, vol. 192, no. 1, pp. 111-117, 2014.

[37] E. M. Kiefer, J. L. Hankinson, and R. G. Barr, "Similar relation of age and height to lung function among Whites, African Americans, and Hispanics," American Journal of Epidemiology, vol. 173, no. 4, pp. 376-387, 2011.

[38] H. Santana, E. Zoico, E. Turcato et al., "Relation between body composition, fat distribution, and lung function in elderly men," The American Journal of Clinical Nutrition, vol. 73, no. 4, pp. 827-831, 2001.

[39] C. Ubilla, P. Bustos, H. Amigo, M. Oyarzun, and R. J. Rona, "Nutritional status, especially body mass index, from birth to adulthood and lung function in young adulthood," Annals of Human Biology, vol. 35, no. 3, pp. 322-333, 2008.

[40] Y. Chen, D. Rennie, Y. F. Cormier, and J. Dosman, "Waist circumference is associated with pulmonary function in normalweight, overweight, and obese subjects," American Journal of Clinical Nutrition, vol. 85, no. 1, pp. 35-39, 2007.

[41] P. Burney, A. Jithoo, B. Kato et al., "Chronic obstructive pulmonary disease mortality and prevalence: the associations with smoking and poverty-a bold analysis," Thorax, vol. 69, no. 5, pp. 465-473, 2014.

[42] P. Boros, M. Franczuk, and S. Wesołowski, "Principles of spirometry results interpretation," Pneumonologia i Alergologia Polska, vol. 72, pp. 7-9, 2004.

[43] O. Ozdemir, N. Numanoglu, U. Gonüllü, I. Savas, D. Alper, and H. Gurses, "Chronic effects of welding exposure on pulmonary function tests and respiratory symptoms," Occupational and Environmental Medicine, vol. 52, no. 12, pp. 800-803, 1995.

[44] J. Szram, S. J. Schofield, M. P. Cosgrove, and P. Cullinan, "Welding, longitudinal lung function decline and chronic respiratory symptoms: a systematic review of cohort studies," European Respiratory Journal, vol. 42, no. 5, pp. 1186-1193, 2013.

[45] G. T. Ferguson, P. L. Enright, A. S. Buist, and M. W. Higgins, "Office spirometry for lung health assessment in adults: a consensus statement from the national lung health education program," Chest, vol. 117, no. 4, pp. 1146-1161, 2000.

[46] J. Zieliñski, M. Bednarek, M. Czajkowska-Malinowska et al., "Early detection of COPD in a high-risk population using spirometric screening," Chest, vol. 119, no. 3, pp. 731-736, 2001.
[47] H. W. Glindmeyer, R. N. Jones, J. E. Diem, and H. Weill, "Useful and extraneous variability in longitudinal assessment of lung function," Chest, vol. 92, no. 5, pp. 877-882, 1987. 


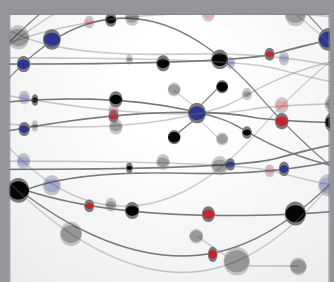

The Scientific World Journal
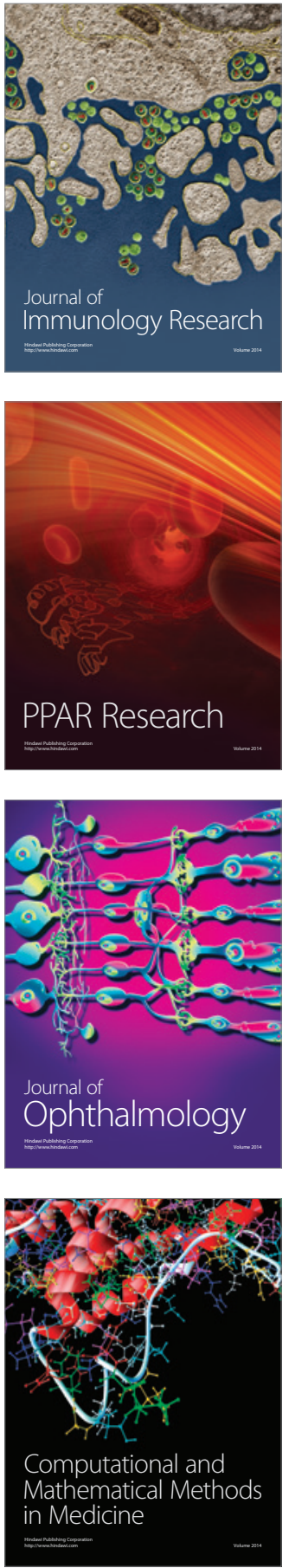

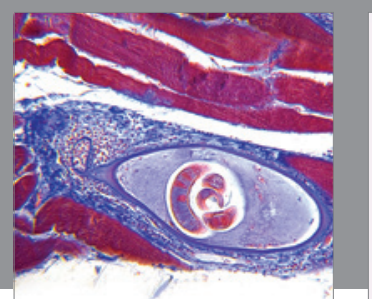

Gastroenterology Research and Practice

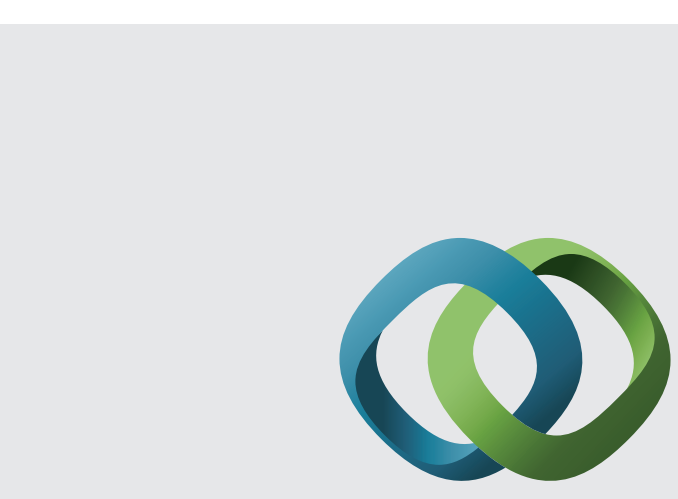

\section{Hindawi}

Submit your manuscripts at

http://www.hindawi.com
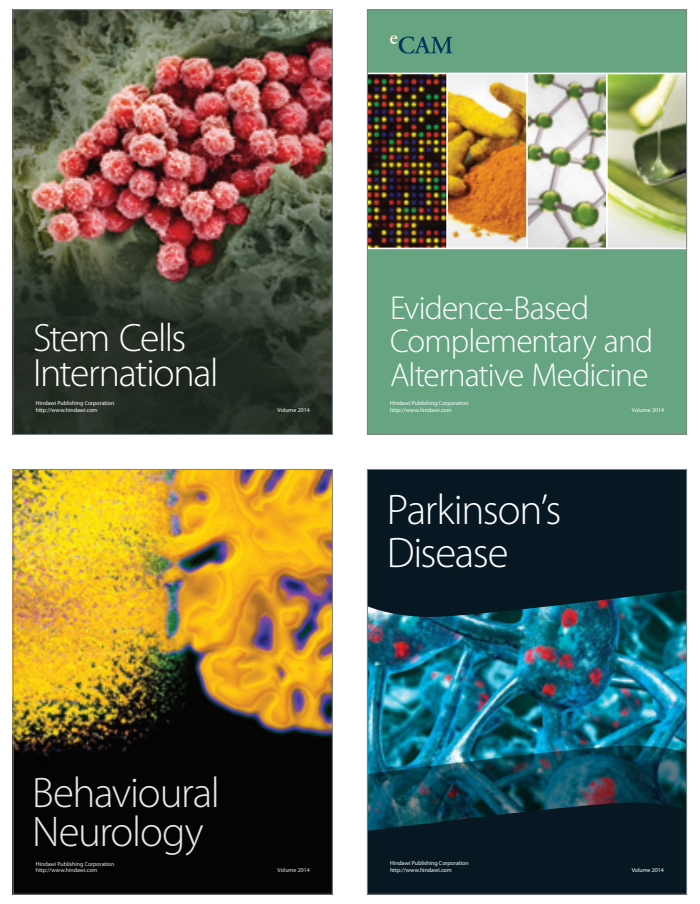
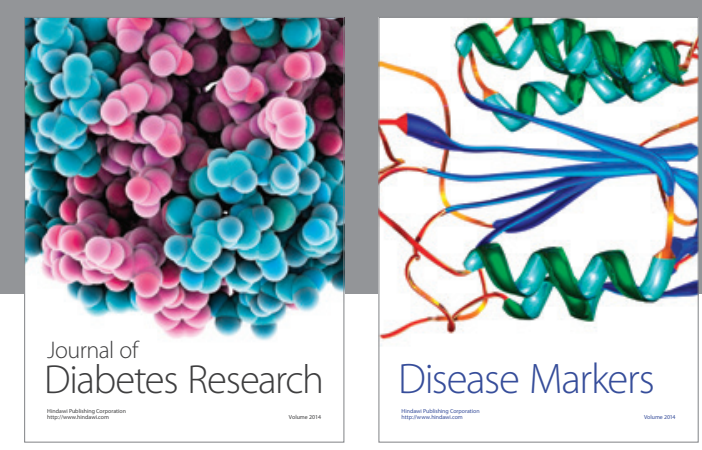

Disease Markers
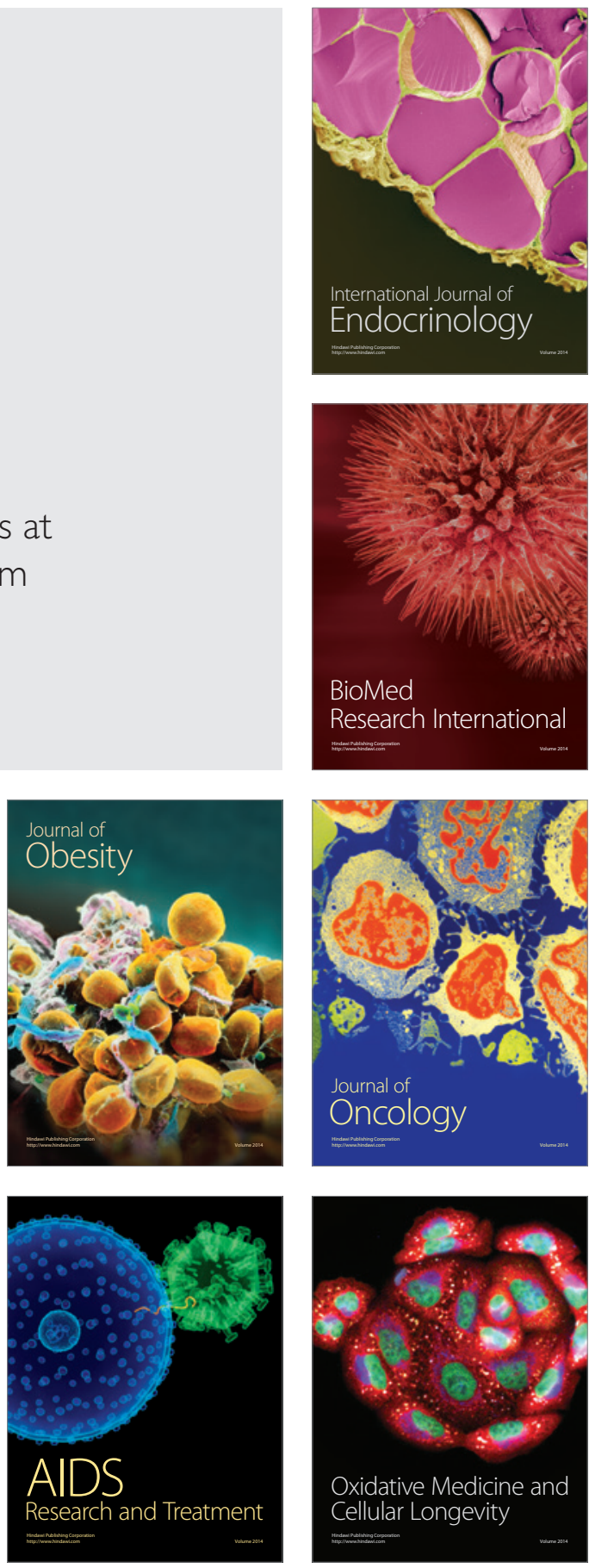